\title{
Analysis and Design Strategy of On-Chip Charge Pumps for Micro-power Energy Harvesting Applications
}

\author{
Wing-Hung $\mathrm{Ki}^{1}$, Yan $\mathrm{Lu}^{1}$, Feng $\mathrm{Su}^{2}$, and Chi-Ying Tsui ${ }^{1}$ \\ ${ }^{1}$ ECE Department, HKUST, Hong Kong \\ \{eeki, yanlu, eetsui\} @ust.hk \\ ${ }^{2}$ Broadcom Corporation, San Jose, CA, USA \\ fsu@broadcom.com
}

\begin{abstract}
Charge balance law based on conservation of charge is stated and employed to analyze on-chip linear, Fibonacci and exponential charge pumps. For micro-power on-chip implementations, both the positive- and the negativeplate parasitic capacitors have to be considered. Voltage conversion ratios and efficiencies can be obtained in closed form for single- and dual-branch linear charge pumps, but not for Fibonacci and exponential charge pumps. Instead, a first iteration approximation analysis for computing voltage conversion ratio is proposed. For the linear charge pump, efficiency optimization is achieved by first computing the optimal number of stages, and then obtaining from the required output voltage the reduction factor that is a function of load current, flying capacitor and switching frequency. Using a $0.35 \mu \mathrm{m}$ CMOS process, $8 \mathrm{X}$ linear, Fibonacci and exponential charge pumps are designed and their performances are compared and confirmed by extensive Cadence Spectre simulations. It is concluded that linear charge pumps attain the best efficiency.
\end{abstract}

Keywords: charge balance, charge pump, charge redistribution, exponential charge pump, Fibonacci charge pump, linear charge pump.

\section{Introduction}

Micro-power energy harvesting and micro-sensor applications require fully on-chip implementation of power management units that include integrated switchedcapacitor power converters, or charge pumps (QPs). Embedded systems that have a stringent silicon estate need fully on-chip charge pumps for reading and writing EEPROM. For on-chip charge pumps, efficiency in power and area are two major concerns, and both are closely related to charge pump topologies that determine the number of capacitors and switches and losses due to parasitic capacitors. Integrated linear (or Dickson) charge pumps (LQPs) are the most popular implementations due to their simple structure and readily available design procedures [1-8]. With a 2-phase non-overlapping clock, the Fibonacci charge pump (FQP) [9] and the exponential charge pump (EQP) $[10,11]$ promised to achieve very high voltage conversion ratios using fewer capacitors than the LQP, and both are potential candidates for on-chip applications. Therefore, there is a practical need in analyzing which charge pump would have the best efficiency using the smallest area of on-chip capacitors. 
Consider a (linear) charge pump with $\mathrm{N}$ flying capacitors and a load capacitor. For each flying capacitor $\mathrm{C}_{\mathrm{k}}$ (the $\mathrm{k}^{\text {th }}$ stage), one plate is always at a higher potential and is called the positive plate, while the other is the negative plate. For an on-chip capacitor $\mathrm{C}_{\mathrm{k}}$, both the positive-plate and negative-plate parasitic capacitors can be considered to be proportional to $\mathrm{C}_{\mathrm{k}}$, namely, $\alpha \mathrm{C}_{\mathrm{k}}$ and $\beta \mathrm{C}_{\mathrm{k}}$, respectively, and they are not negligibly small. In [2], the output voltage $\mathrm{V}_{\mathrm{o}}$ was derived by assuming that all $\mathrm{C}_{\mathrm{k}}$ are equal and the load capacitor $C_{L}$ is infinite, and equal $C_{k}$ gives the smallest total capacitance in maximizing $\mathrm{V}_{\mathrm{o}}$ [1]. The exact argument of how to charge up an infinite capacitor was not presented, and the efficiency was not considered. The Dickson derivation of [2] used heuristic reasoning in accounting for $\alpha \mathrm{C}_{\mathrm{k}}$ and formed the basis of many subsequent analyses [3-8]. Evidently, a more solid derivation on par with circuit analysis using Kirchhoff's current and voltage laws is needed. In [3], the authors commented that the output voltage ripple $\Delta \mathrm{V}_{\mathrm{o}}$ could be added back to the case with $\mathrm{C}_{\mathrm{L}}=\infty$, but gave no computation details. Nevertheless, the major concern of [3] (and [8]) was to compute the non-ideal effect of the transistor switches. In [4], both the load capacitor and the parasitic capacitors were not considered in analyzing the Dickson charge pump, and no efficiency information was given. In [5] (and [7], an extended version of [5]), the correct equation for the output voltage of an ideal linear charge pump with different $C_{k}$ and an infinite $C_{L}$ was put down without elaboration. More importantly, it presents a design procedure that minimizes the input current, which is equivalent to maximize the power conversion efficiency $\eta$. However, $\alpha C_{k}$ are ignored in [5] as the authors argue that the major contributions of loss are from $\beta C_{k}$. To improve the analysis of [5], both $\alpha C_{k}$ and $\beta C_{k}$ are included in [6], but it assumes that all $\alpha \mathrm{C}_{\mathrm{k}}$ are charged in both phases, while in the steady state, any capacitor should have alternate charging and discharging phases in one cycle. Despite the deficiencies, [5] and [6] are among the very few publications that presented formulae for computing efficiency. While analyses of LQPs are numerous, there is no corresponding analysis for FQPs and EQPs, and they could not be easily analyzed by the Dickson derivation.

In this research, the linear charge pump with parasitic capacitors and a finite load capacitor is analyzed. Ideal switches are assumed, as non-ideal switches lead to incomplete charge transfer that should be dealt with in a separate work. Analysis on charge transfer and charge redistribution is based on systematic application of the charge balance law (QBL) to be discussed in Section 2 [12, 13]. The output voltage $\mathrm{V}_{\mathrm{o}}(\mathrm{t})$ and the average output voltage $\mathrm{V}_{\mathrm{o}}$ are derived in Section 3, the power conversion efficiency $\eta$ in Section 4 , and $V_{o}$ and $\eta$ of the dual-branch linear charge pump in Section 5. Cadence Spectre simulation results of single- and dual-branch linear charge pumps are presented in Section 6. The first iteration approximation analysis is employed in analyzing Fibonacci and exponential charge pumps in Section 7 and Section 8, respectively [14]. All charge pumps are compared in Section 9. After concluding that the linear charge pump is the most efficient on-chip implementation with the smallest area, a detail design strategy is proposed in Section 10, followed by some concluding remarks in Section 11. 


\section{Charge Balance Law}

In circuit analysis, we use Kirchhoff's current law and Kirchhoff's voltage law systematically to solve problems. It is beneficial to have a similar law for analyzing switched-capacitor circuits including charge pumps. In fact, to facilitate the computation of charge transfer, a law that is based on conservation of charge can be formulated. The charge balance law (QBL) says

\section{In a system of capacitors, the sum of all charges leaving a node at any instance of charge transfer is equal to zero.}

It is obvious that the term "leaving a node" can be replaced by "entering a node" with the same validity. This law was first named Kirchhoff's charge law in [12] and then in [13], but is better be renamed as the charge balance law. It is also known simply as charge balance in [15]. Fig. 1 shows $n$ capacitors $\left(C_{1}, C_{2}, \ldots, C_{n}\right)$ to be connected at the node $\mathrm{V}_{\mathrm{a}}$ at $\mathrm{t}=\mathrm{t}_{\mathrm{o}}$. For each capacitor, one plate will be connected to $\mathrm{V}_{\mathrm{a}}$ and let $\mathrm{us}$ arbitrarily assign that plate to be the positive plate, while the negative plate will be connected to other circuit components not shown. Prior to the charge transfer, the corresponding capacitor voltages are $\mathrm{V}_{\mathrm{C} 1}\left(\mathrm{t}_{\mathrm{o}}{ }^{-}\right), \mathrm{V}_{\mathrm{C} 2}\left(\mathrm{t}_{\mathrm{o}}{ }^{-}\right), \ldots, \mathrm{V}_{\mathrm{Cn}}\left(\mathrm{t}_{\mathrm{o}}^{-}\right)$, and at $\mathrm{t}=\mathrm{t}_{\mathrm{o}}$, charge transfer occurs, such that when charge redistribution is completed, the capacitor voltages are $\mathrm{V}_{\mathrm{C} 1}\left(\mathrm{t}_{\mathrm{o}}^{+}\right), \mathrm{V}_{\mathrm{C} 2}\left(\mathrm{t}_{\mathrm{o}}^{+}\right), \ldots, \mathrm{V}_{\mathrm{Cn}}\left(\mathrm{t}_{\mathrm{o}}^{+}\right)$. Employing QBL we have

$$
\sum_{\mathrm{k}=1}^{\mathrm{n}} \mathrm{C}_{\mathrm{k}} \mathrm{V}_{\mathrm{Ck}}\left(\mathrm{t}_{\mathrm{o}}{ }^{-}\right)=\sum_{\mathrm{k}=1}^{\mathrm{n}} \mathrm{C}_{\mathrm{k}} \mathrm{V}_{\mathrm{Ck}}\left(\mathrm{t}_{\mathrm{o}}^{+}\right)
$$

A simple way to apply QBL is to remember

$$
\text { Total Initial Charge }=\text { Total Final Charge } .
$$

In this paper, all equations accounting for charge transfer are written in the form of (2).

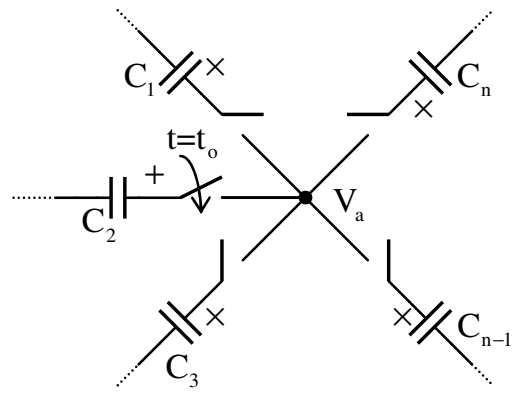

Fig. 1. Charge redistribution at the node $V_{a}$ 


\section{Analysis of Single-Branch Linear Charge Pumps}

Fig. 2 shows a single-branch $\mathrm{N}$-stage linear charge pump (LQP) with a voltage conversion ratio $\mathrm{M}\left(=\mathrm{V}_{\mathrm{o}} / \mathrm{V}_{\mathrm{dd}}\right)$ that is equal to $\mathrm{N}+1$ if the load current is zero. The analysis is simplified by having a load current $\mathrm{I}_{\mathrm{o}}$ instead of a load resistor. The case using ideal switches and no parasitic capacitor has been derived in [13]. We now turn to the general case that any on-chip (flying) capacitor $C_{k}$ has both positive-plate and negative-plate parasitic capacitors $\alpha \mathrm{C}_{\mathrm{k}}$ and $\beta \mathrm{C}_{\mathrm{k}}$ to ground.

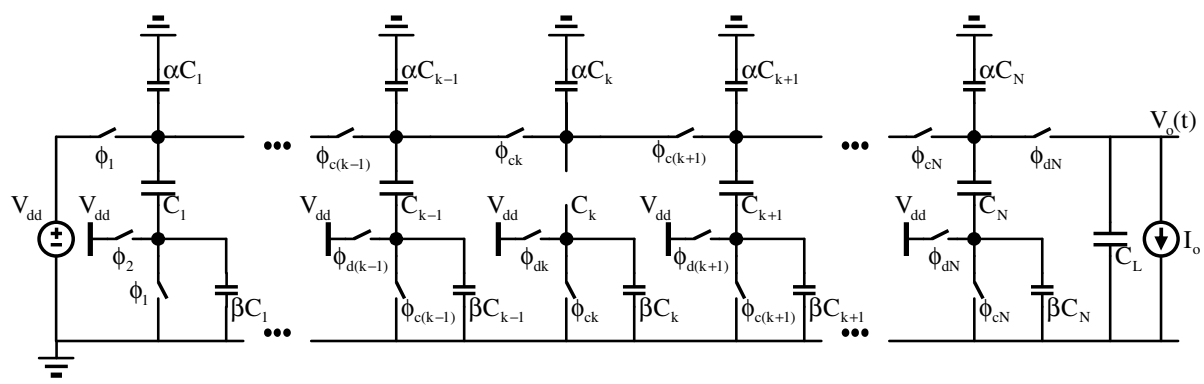

Fig. 2. Single-branch $(\mathrm{N}+1) \mathrm{X}$ linear charge pump with parasitic capacitors

Fig. 3 shows the voltages across the capacitors $C_{k}, \alpha C_{k}$ and $C_{L}$. Every capacitor $C_{x}$ has a charging phase $\phi_{\mathrm{cx}}$ and a discharging phase $\phi_{\mathrm{dx}}$. For example, for $\mathrm{k}$ even, the charging phase of $\mathrm{C}_{\mathrm{k}}$ is $\phi_{\mathrm{ck}}=\phi_{2}$. We assign $\mathrm{V}_{\mathrm{k}}$ as the capacitor voltage of $\mathrm{C}_{\mathrm{k}}$ (at the end) of its discharging phase. The analysis of charge pumps involves mundane charge accounting, and our experience tells us that it is more efficient to work from the output side towards the input side. Fig. 3(d) shows the time-varying output voltage $\mathrm{V}_{\mathrm{o}}(\mathrm{t})$, and let $\mathrm{V}_{\mathrm{o} 1}$ be the output voltage at the beginning of the discharging phase of $\mathrm{C}_{\mathrm{N}}\left(\phi_{\mathrm{dN}}=1\right)$. During $\phi_{\mathrm{dN}}=1$, the load current $\mathrm{I}_{\mathrm{o}}$ discharges $\mathrm{C}_{\mathrm{N}}$ and $\mathrm{C}_{\mathrm{L}}$ for half of the clock period $\mathrm{T} / 2$, and

$$
\mathrm{V}_{\mathrm{o} 1}=\mathrm{V}_{\mathrm{o} 2}+\frac{\mathrm{I}_{\mathrm{o}} \mathrm{T} / 2}{(1+\alpha) \mathrm{C}_{\mathrm{N}}+\mathrm{C}_{\mathrm{L}}}
$$

During the next phase $\phi_{\mathrm{cN}}=1, \mathrm{C}_{\mathrm{N}}$ is disconnected from $\mathrm{C}_{\mathrm{L}}$, and the load current discharges $\mathrm{C}_{\mathrm{L}}$ and gives

$$
\mathrm{V}_{\mathrm{o} 3}=\mathrm{V}_{\mathrm{o} 2}-\frac{\mathrm{I}_{\mathrm{o}} \mathrm{T} / 2}{\mathrm{C}_{\mathrm{L}}}
$$

The output voltage ripple $\Delta \mathrm{V}_{\mathrm{o}}$ is immediately given by

$$
\Delta \mathrm{V}_{\mathrm{o}}=\mathrm{V}_{\mathrm{o} 1}-\mathrm{V}_{\mathrm{o} 3}=\frac{\mathrm{I}_{\mathrm{o}} \mathrm{T}}{2} \frac{1}{\mathrm{C}_{\mathrm{L}} \|\left[(1+\alpha) \mathrm{C}_{\mathrm{N}}+\mathrm{C}_{\mathrm{L}}\right]} .
$$



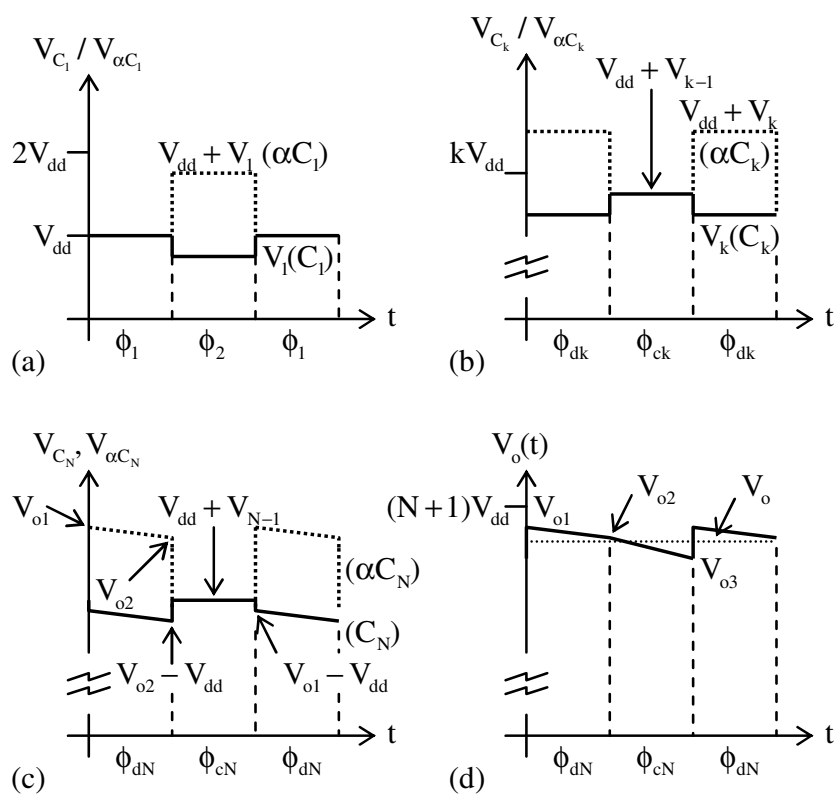

Fig. 3. Capacitor and output voltages of LQP: (a) $V_{C 1}$ and $V_{\alpha C 1}$; (b) $V_{C k}$ and $V_{\alpha C k}$; (c) $V_{C N}$ and $\mathrm{V}_{\alpha \mathrm{CN}} ;$ and $(\mathrm{d}) \mathrm{V}_{\mathrm{o}}(\mathrm{t})$

While $C_{L}$ is discharged by $I_{o}, C_{N}$ is being charged up, and the charging phase of $C_{N}$ is the discharging phase of $\mathrm{C}_{\mathrm{N}-1}$. Therefore, in $\phi_{\mathrm{cN}}=1, \mathrm{C}_{\mathrm{N}-1}$ is discharged to $\mathrm{V}_{\mathrm{N}-1}, \mathrm{C}_{\mathrm{N}}$ is charged to $\mathrm{V}_{\mathrm{dd}}+\mathrm{V}_{\mathrm{N}-1}$, and $\alpha \mathrm{C}_{\mathrm{N}}$ is discharged to $\mathrm{V}_{\mathrm{dd}}+\mathrm{V}_{\mathrm{N}-1}$. In fact, it will become clear later that while the flying capacitor $C_{k}$ is being charged up, $\alpha C_{k}$ is being discharged (Fig. 4). At the start of the next clock phase, that is, at the instant of $\phi_{\mathrm{dN}}=1$ again, $\mathrm{C}_{\mathrm{N}}$ redistributes charge with $C_{L}$ such that $V_{o}(t)$ is pumped up from $V_{03}$ to $V_{o 1}$. Employ QBL gives

$$
(1+\alpha) \mathrm{C}_{\mathrm{N}}\left(\mathrm{V}_{\mathrm{dd}}+\mathrm{V}_{\mathrm{N}-1}\right)+\mathrm{C}_{\mathrm{L}} \mathrm{V}_{\mathrm{o} 3}=\mathrm{C}_{\mathrm{N}}\left(\mathrm{V}_{\mathrm{o} 1}-\mathrm{V}_{\mathrm{dd}}\right)+\alpha \mathrm{C}_{\mathrm{N}} \mathrm{V}_{\mathrm{o} 1}+\mathrm{C}_{\mathrm{L}} \mathrm{V}_{\mathrm{o} 1} .
$$

In substituting (3) and (4) into (6) we have

$$
\mathrm{V}_{\mathrm{o} 2}=\frac{2+\alpha}{1+\alpha} \mathrm{V}_{\mathrm{dd}}+\mathrm{V}_{\mathrm{N}-1}-\frac{\mathrm{I}_{\mathrm{o}} \mathrm{T}}{(1+\alpha) \mathrm{C}_{\mathrm{N}}} .
$$

Next, consider the charge redistribution of $\mathrm{C}_{\mathrm{N}-1}$ with $\mathrm{C}_{\mathrm{N}}$, and QBL gives

$$
\begin{array}{r}
(1+\alpha) C_{\mathrm{N}-1}\left(\mathrm{~V}_{\mathrm{dd}}+\mathrm{V}_{\mathrm{N}-2}\right)+\mathrm{C}_{\mathrm{N}}\left(\mathrm{V}_{\mathrm{o} 2}-\mathrm{V}_{\mathrm{dd}}\right)+\alpha \mathrm{C}_{\mathrm{N}} \mathrm{V}_{\mathrm{o} 2}= \\
\mathrm{C}_{\mathrm{N}-1} \mathrm{~V}_{\mathrm{N}-1}+\alpha \mathrm{C}_{\mathrm{N}-1}\left(\mathrm{~V}_{\mathrm{dd}}+\mathrm{V}_{\mathrm{N}-1}\right)(1+\alpha) \mathrm{C}_{\mathrm{N}}\left(\mathrm{V}_{\mathrm{dd}}+\mathrm{V}_{\mathrm{N}-1}\right)
\end{array} .
$$

In making use of (7), (8) can be simplified to

$$
\mathrm{V}_{\mathrm{N}-1}=\frac{1}{1+\alpha} \mathrm{V}_{\mathrm{dd}}+\mathrm{V}_{\mathrm{N}-2}-\frac{\mathrm{I}_{\mathrm{o}} \mathrm{T}}{(1+\alpha) \mathrm{C}_{\mathrm{N}-1}}
$$




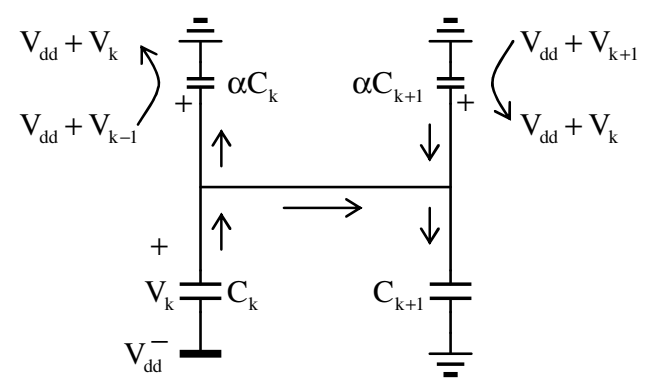

Fig. 4. Capacitor $C_{k}$ in discharging phase

We then consider the general $\mathrm{k}^{\text {th }}$ stage, such that $\mathrm{C}_{\mathrm{k}}$ is charged up by $\mathrm{C}_{\mathrm{k}-1}$ in its charging phase $\phi_{\mathrm{ck}}$, and redistributes charge with $\mathrm{C}_{\mathrm{k}+1}$ during its discharging phase $\phi_{\mathrm{dk}}$. Employ QBL and an equation similar to (8) can be written down. By grouping the terms involving $\mathrm{C}_{\mathrm{k}}$ and $\mathrm{C}_{\mathrm{k}+1}$ on different side we obtain

$$
\mathrm{C}_{\mathrm{k}} \mathrm{V}_{\mathrm{dd}}+(1+\alpha) \mathrm{C}_{\mathrm{k}} \mathrm{V}_{\mathrm{k}-1}-(1+\alpha) \mathrm{C}_{\mathrm{k}} \mathrm{V}_{\mathrm{k}}=\mathrm{C}_{\mathrm{k}+1} \mathrm{~V}_{\mathrm{dd}}+(1+\alpha) \mathrm{C}_{\mathrm{k}+1} \mathrm{~V}_{\mathrm{k}}-(1+\alpha) \mathrm{C}_{\mathrm{k}+1} \mathrm{~V}_{\mathrm{k}+1}
$$

An immediate relation is revealed if we consider $\mathrm{k}=\mathrm{N}-2$ such that the right hand side of (10) is equal to $I_{o} T$, and (10) is the same as (9) with a different index. Clearly, the same relation propagates down the charge pump, and we can rewrite (10) as

$$
\mathrm{V}_{\mathrm{k}}=\frac{1}{1+\alpha} \mathrm{V}_{\mathrm{dd}}+\mathrm{V}_{\mathrm{k}-1}-\frac{\mathrm{I}_{\mathrm{o}} \mathrm{T}}{(1+\alpha) \mathrm{C}_{\mathrm{k}}}
$$

However, $\mathrm{C}_{1}$ has no prior stage, and $\mathrm{V}_{0}\left(\right.$ not $\left.\mathrm{V}_{\mathrm{o}}\right)$ is zero, that is,

$$
\mathrm{V}_{1}=\frac{1}{1+\alpha} \mathrm{V}_{\mathrm{dd}}-\frac{\mathrm{I}_{\mathrm{o}} \mathrm{T}}{(1+\alpha) \mathrm{C}_{1}}
$$

The interpretation of (11) is that the overall change in charge of each flying capacitor in one cycle is the amount of charge $\mathrm{I}_{\mathrm{o}} \mathrm{T}$ delivered to the adjacent higher stage in the same cycle. This charge transfer is independent of $\mathrm{C}_{\mathrm{L}}$. Consider that when $\mathrm{C}_{\mathrm{k}}$ is charged to $\mathrm{V}_{\mathrm{dd}}+\mathrm{V}_{\mathrm{k}-1}$, the voltage across $\alpha \mathrm{C}_{\mathrm{k}}$ is also $\mathrm{V}_{\mathrm{dd}}+\mathrm{V}_{\mathrm{k}-1}$. When $\mathrm{C}_{\mathrm{k}}$ is discharged to $\mathrm{V}_{\mathrm{k}}$, the voltage across $\alpha \mathrm{C}_{\mathrm{k}}$ is $\mathrm{V}_{\mathrm{dd}}+\mathrm{V}_{\mathrm{k}}$. It is clear from (11) that $\mathrm{V}_{\mathrm{dd}}+\mathrm{V}_{\mathrm{k}}$ is larger than $\mathrm{V}_{\mathrm{dd}}+\mathrm{V}_{\mathrm{k}-1}$. Hence, when $\mathrm{C}_{\mathrm{k}}$ is being charged, $\alpha \mathrm{C}_{\mathrm{k}}$ is being discharged, but in [6], $\alpha \mathrm{C}_{\mathrm{k}}$ is assumed to be charged in both phases. Next, substitute (9), (11) and (12) into (7), and we have

$$
\mathrm{V}_{\mathrm{o} 2}=\frac{\mathrm{N}+1+\alpha}{1+\alpha} \mathrm{V}_{\mathrm{dd}}-\sum_{\mathrm{k}=1}^{\mathrm{N}} \frac{\mathrm{I}_{\mathrm{o}} \mathrm{T}}{(1+\alpha) \mathrm{C}_{\mathrm{k}}}
$$

An important observation is that $\mathrm{V}_{\mathrm{o} 2}$ is independent of $\mathrm{C}_{\mathrm{L}}$, and this property is very useful in simplifying the analysis for the case of $\mathrm{C}_{\mathrm{L}}=\infty$. From $\mathrm{V}_{\mathrm{o} 2}$, one can write down $\mathrm{V}_{\mathrm{o} 1}$ and $\mathrm{V}_{\mathrm{o} 3}$ from (3) and (4) easily: 


$$
\begin{gathered}
\mathrm{V}_{\mathrm{o} 1}=\frac{\mathrm{N}+1+\alpha}{1+\alpha} \mathrm{V}_{\mathrm{dd}}-\sum_{\mathrm{k}=1}^{\mathrm{N}} \frac{\mathrm{I}_{\mathrm{o}} \mathrm{T}}{(1+\alpha) \mathrm{C}_{\mathrm{k}}}+\frac{\mathrm{I}_{\mathrm{o}} \mathrm{T} / 2}{(1+\alpha) \mathrm{C}_{\mathrm{N}}+\mathrm{C}_{\mathrm{L}}}, \\
\mathrm{V}_{\mathrm{o} 3}=\frac{\mathrm{N}+1+\alpha}{1+\alpha} \mathrm{V}_{\mathrm{dd}}-\sum_{\mathrm{k}=1}^{\mathrm{N}} \frac{\mathrm{I}_{\mathrm{o}} \mathrm{T}}{(1+\alpha) \mathrm{C}_{\mathrm{k}}}-\frac{\mathrm{I}_{\mathrm{o}} \mathrm{T} / 2}{\mathrm{C}_{\mathrm{L}}}
\end{gathered}
$$

The average output voltage can be computed from Fig. 3(d) by averaging the areas of trapezoids as $\mathrm{V}_{\mathrm{o}}=\left(\mathrm{V}_{\mathrm{o} 1}+2 \mathrm{~V}_{\mathrm{o} 2}+\mathrm{V}_{\mathrm{o} 3}\right) / 4$, that is,

$$
\mathrm{V}_{\mathrm{o}}=\frac{\mathrm{N}+1+\alpha}{1+\alpha} \mathrm{V}_{\mathrm{dd}}-\sum_{\mathrm{k}=1}^{\mathrm{N}} \frac{\mathrm{I}_{\mathrm{o}} \mathrm{T}}{(1+\alpha) \mathrm{C}_{\mathrm{k}}}-\frac{\mathrm{I}_{\mathrm{o}} \mathrm{T}}{8}\left(\frac{1}{\mathrm{C}_{\mathrm{L}}}-\frac{1}{(1+\alpha) \mathrm{C}_{\mathrm{N}}+\mathrm{C}_{\mathrm{L}}}\right)
$$

A practical capacitance assignment requires $C_{L}>C_{k}$, and usually, $C_{L}>>C_{k}$, and the effect of $C_{L}$ is negligibly small; or equivalently, we may assume $C_{L} \rightarrow \infty$, such that $\mathrm{V}_{\mathrm{o}}=\mathrm{V}_{\mathrm{o} 2}$. To maximize $\mathrm{V}_{\mathrm{o} 2}\left(\approx \mathrm{V}_{\mathrm{o}}\right)$ and minimize the total capacitance $\mathrm{C}_{\mathrm{T}}$ it is clear that all $\mathrm{C}_{\mathrm{k}}$ should be set equal $[1,13]$ :

$$
\mathrm{C}_{1}=\mathrm{C}_{2}=\ldots=\mathrm{C}_{\mathrm{N}}=\mathrm{C} \text {. }
$$

The total capacitance $\mathrm{C}_{\mathrm{T}}$ is

$$
\mathrm{C}_{\mathrm{T}}=\mathrm{NC},
$$

and the output voltage and the output voltage ripple (with $C_{L}>>C_{k}$ ) are then given by

$$
\begin{gathered}
\mathrm{V}_{\mathrm{o}}=\frac{\mathrm{N}+1+\alpha}{1+\alpha} \mathrm{V}_{\mathrm{dd}}-\frac{\mathrm{NI}_{\mathrm{o}} \mathrm{T}}{(1+\alpha) \mathrm{C}}, \\
\Delta \mathrm{V}_{\mathrm{o}}=\frac{\mathrm{I}_{\mathrm{o}} \mathrm{T}}{\mathrm{C}_{\mathrm{L}}} .
\end{gathered}
$$

Let us define the reduction factor $\delta$ as the fractional voltage drop per stage due to the load current $\mathrm{I}_{\mathrm{o}}$ with the flying capacitor equal to $\mathrm{C}$ :

$$
\delta=\frac{\mathrm{I}_{\mathrm{o}} \mathrm{T}}{\mathrm{CV}_{\mathrm{dd}}}
$$

The voltage conversion ratio $\mathrm{M}$ can then be written as

$$
\mathrm{M}=\frac{\mathrm{V}_{\mathrm{o}}}{\mathrm{V}_{\mathrm{dd}}}=\frac{\mathrm{N}+1+\alpha-\mathrm{N} \delta}{1+\alpha}
$$

As $\alpha$ (as well as $\beta$ ) is fixed in a fabrication process, the only way to increase the output voltage $\mathrm{V}_{\mathrm{o}}\left(=\mathrm{MV}_{\mathrm{dd}}\right)$ is to use a small $\delta$, that is, to use a large $\mathrm{C}$ or a high switching frequency $\mathrm{f}_{\mathrm{s}}(=1 / \mathrm{T})$ as design constraints allow. In Section 4 , we will show that this criterion is in conflict with maximizing the efficiency in the presence of parasitic capacitors. 


\section{Efficiency Optimization of Linear Charge Pumps}

After obtaining the output voltage as a function of capacitors, switching frequency and load current, the next is to compute and optimize the efficiency $\eta$. Let $E_{i}$ be the input energy supplied by $V_{d d}$ in one cycle, and $E_{o}$ the output energy consumed by the load in the same cycle. The efficiency of a charge pump is given by

$$
\eta=\frac{E_{o}}{E_{i}} .
$$

The term $\mathrm{E}_{\mathrm{o}}$ is simply given by

$$
\mathrm{E}_{\mathrm{o}}=\mathrm{V}_{\mathrm{o}} \mathrm{I} \mathrm{T} \text {. }
$$

With reference to Fig. 2, the term $\mathrm{E}_{\mathrm{i}}$ supplied by $\mathrm{V}_{\mathrm{dd}}$ can be divided into three types: (1) $E_{i 1}$ is the cycle energy delivered to the positive plates of $C_{1}$ and $\alpha C_{1}$ when being charged; (2) $E_{i 2 k}$ is the cycle energy delivered to the negative plate of $C_{k}$ when it is discharged; and (3) $E_{i 3 k}$ is the cycle energy delivered to the positive plates of $\beta C_{k}$ when being charged. Hence,

$$
\mathrm{E}_{\mathrm{i}}=\mathrm{E}_{\mathrm{i} 1}+\sum_{\mathrm{k}=1}^{\mathrm{N}} \mathrm{E}_{\mathrm{i} 2 \mathrm{k}}+\sum_{\mathrm{k}=1}^{\mathrm{N}} \mathrm{E}_{\mathrm{i} 3 \mathrm{k}} .
$$

First of all, consider $C_{1}$ being charged by $V_{d d}$. With reference to Fig. 3(a), when $C_{1}$ is previously discharged to $\mathrm{V}_{1}, \alpha \mathrm{C}_{1}$ is charged to $\left(\mathrm{V}_{\mathrm{dd}}+\mathrm{V}_{1}\right)$. In the charging phase of $\mathrm{C}_{1}$, if we assume there is no reversion loss, that is, the charge $\alpha C_{1}\left(V_{d d}+V_{1}\right)$ entirely redistributes with $\mathrm{C}_{1}$ first before $\mathrm{C}_{1}$ is charged by $\mathrm{V}_{\mathrm{dd}}$, then the charge $\Delta \mathrm{Q}_{\mathrm{i} 1}$ supplied by $\mathrm{V}_{\mathrm{dd}}$ is

$$
\mathrm{C}_{1} \mathrm{~V}_{1}+\alpha \mathrm{C}_{1}\left(\mathrm{~V}_{\mathrm{dd}}+\mathrm{V}_{1}\right)+\Delta \mathrm{Q}_{\mathrm{i} 1}=(1+\alpha) \mathrm{C}_{1} \mathrm{~V}_{\mathrm{dd}}
$$

Using (12) and that $\mathrm{E}_{\mathrm{i} 1}$ is equal to $\mathrm{V}_{\mathrm{dd}} \Delta \mathrm{Q}_{\mathrm{il}}$, we have

$$
\mathrm{E}_{\mathrm{i} 1}=\mathrm{V}_{\mathrm{dd}} \mathrm{I}_{\mathrm{o}} \mathrm{T} \text {. }
$$

In computing $E_{i 2 k}$, denote the charge that is lost on the positive plate of $C_{k}$ in its discharging phase as $\Delta \mathrm{Q}_{\mathrm{i} 2 \mathrm{k}}$, and this charge has to be supplied by $\mathrm{V}_{\mathrm{dd}}$ to the negative plate of $\mathrm{C}_{\mathrm{k}}$. Hence, for $\mathrm{C}_{\mathrm{k}}(\mathrm{k} \neq \mathrm{N})$, we have

$$
\mathrm{C}_{\mathrm{k}}\left(\mathrm{V}_{\mathrm{dd}}+\mathrm{V}_{\mathrm{k}-1}\right)-\Delta \mathrm{Q}_{\mathrm{i} 2 \mathrm{k}}=\mathrm{C}_{\mathrm{k}} \mathrm{V}_{\mathrm{k}} \text {. }
$$

Using (11) and that $\mathrm{E}_{\mathrm{i} 2 \mathrm{k}}$ is equal to $\mathrm{V}_{\mathrm{dd}} \Delta \mathrm{Q}_{\mathrm{i} 2 \mathrm{k}}$, we have

$$
\mathrm{E}_{\mathrm{i} 2 \mathrm{k}}=\frac{1}{1+\alpha}\left(\mathrm{V}_{\mathrm{dd}} \mathrm{I}_{\mathrm{o}} \mathrm{T}+\alpha \mathrm{C}_{\mathrm{k}} \mathrm{V}_{\mathrm{dd}}^{2}\right) \text {. }
$$

Special care is needed for $\mathrm{C}_{\mathrm{N}}$, as its discharging phase consists of two parts. The first part is for $\mathrm{C}_{\mathrm{N}}$ to redistribute charge with $\mathrm{C}_{\mathrm{L}}$, and the charge supplied by $\mathrm{V}_{\mathrm{dd}}$ is $\Delta \mathrm{Q}_{\mathrm{i} 2 \mathrm{~N} 1}$ :

$$
\mathrm{C}_{\mathrm{N}}\left(\mathrm{V}_{\mathrm{dd}}+\mathrm{V}_{\mathrm{N}-1}\right)-\Delta \mathrm{Q}_{\mathrm{i} 2 \mathrm{~N} 1}=\mathrm{C}_{\mathrm{N}}\left(\mathrm{V}_{\mathrm{o} 1}-\mathrm{V}_{\mathrm{dd}}\right) \text {. }
$$


The second part is discharging $C_{N}$ and $C_{L}$ by $I_{o}$ for half of the period, and the charge supplied by $\mathrm{V}_{\mathrm{dd}}$ to $\mathrm{C}_{\mathrm{N}}$ is $\Delta \mathrm{Q}_{\mathrm{i} 2 \mathrm{~N} 2}$ :

$$
\mathrm{C}_{\mathrm{N}}\left(\mathrm{V}_{\mathrm{o} 1}-\mathrm{V}_{\mathrm{dd}}\right)-\Delta \mathrm{Q}_{\mathrm{i} 2 \mathrm{~N} 2}=\mathrm{C}_{\mathrm{N}}\left(\mathrm{V}_{\mathrm{o} 2}-\mathrm{V}_{\mathrm{dd}}\right) \text {. }
$$

Using (7) in (31), and that the total cycle energy $\mathrm{E}_{\mathrm{i} 2 \mathrm{~N}}$ is given by $\mathrm{V}_{\mathrm{dd}}\left(\Delta \mathrm{Q}_{\mathrm{i} 2 \mathrm{~N} 1}+\Delta \mathrm{Q}_{\mathrm{i} 2 \mathrm{~N} 2}\right)$, we have

$$
\mathrm{E}_{\mathrm{i} 2 \mathrm{~N}}=\frac{1}{1+\alpha}\left(\mathrm{V}_{\mathrm{dd}} \mathrm{I}_{\mathrm{o}} \mathrm{T}+\alpha \mathrm{C}_{\mathrm{N}} \mathrm{V}_{\mathrm{dd}}{ }^{2}\right) .
$$

Here we proved that $\mathrm{E}_{\mathrm{i} 2 \mathrm{~N}}$ is independent of $\mathrm{C}_{\mathrm{L}}$ and has the same form as $\mathrm{E}_{\mathrm{i} 2 \mathrm{k}}$. For the negative-plate parasitic capacitors, it is easy to obtain $\mathrm{E}_{\mathrm{i} 3 \mathrm{k}}$ as

$$
\mathrm{E}_{\mathrm{i} 3 \mathrm{k}}=\beta \mathrm{C}_{\mathrm{k}} \mathrm{V}_{\mathrm{dd}}^{2} \text {. }
$$

From Section 3, the optimal capacitor assignment is $\mathrm{C}_{\mathrm{k}}=\mathrm{C}$. Therefore, in combining (27), (29), (32) and (33) we have

$$
\eta=\frac{\mathrm{V}_{\mathrm{o}} \mathrm{I}_{\mathrm{o}} \mathrm{T}}{\left(1+\frac{\mathrm{N}}{1+\alpha}\right) \mathrm{V}_{\mathrm{dd}} \mathrm{I}_{\mathrm{o}} \mathrm{T}+\frac{\alpha}{1+\alpha} \mathrm{NCV}_{\mathrm{dd}}{ }^{2}+\beta \mathrm{NCV}_{\mathrm{dd}}{ }^{2}} .
$$

From the above discussion, we observe that the input cycle energy $\mathrm{E}_{\mathrm{i}}$ is independent of $\mathrm{C}_{\mathrm{L}}$. In fact, $\mathrm{C}_{\mathrm{L}}$ plays an important role in determining the output voltage ripple (5), but has a negligible effect on the average output voltage (16). For all practical purposes, we may assume $C_{L}=\infty$, and (34) can be written as

$$
\eta=\frac{N+1+\alpha-N \delta}{N+1+\alpha+\frac{N(\alpha+\beta+\alpha \beta)}{\delta}} .
$$

The reduction factor $\delta$ is required to be small if the output voltage has to be as large as possible, for example, $\delta<0.05$. However, a small $\delta$ is achieved by a large $\mathrm{C}$, which translates to large losses of $\alpha \mathrm{CV}_{\mathrm{dd}}{ }^{2}$ and $\beta \mathrm{CV}_{\mathrm{dd}}{ }^{2}$. From (35), both the positive-plate and negative-plate parasitic capacitors have comparable effect on the efficiency. To maximize efficiency, if $\mathrm{N}$ is fixed, the only parameter that can be changed is $\delta$, and we need to solve for the condition $\mathrm{d} \eta / \mathrm{d} \delta=0$. To make the differentiation easier, we rewrite (35) as

$$
\eta=\frac{\delta(1-\mu \delta)}{(\mu \lambda+\delta)}
$$

with

$$
\begin{gathered}
\mu=\frac{N}{N+1+\alpha}, \\
\lambda=\alpha+\beta+\alpha \beta .
\end{gathered}
$$


The optimal reduction factor is obtained as

$$
\delta_{\mathrm{opt}}=\mu \lambda\left(\sqrt{1+\frac{1}{\mu^{2} \lambda}}-1\right)
$$

and the corresponding maximum efficiency is

$$
\eta_{\max }=1-2 \mu \delta_{\text {opt }} .
$$

However, if a predefined $\mathrm{V}_{\mathrm{o}}$ has to be achieved, $\delta_{\text {opt }}$ obtained in (39) may not satisfy (22). To satisfy (22), we substitute

$$
\delta=\frac{N+1+\alpha-(1+\alpha) M}{N}
$$

into (35) and obtain

$$
\eta=\frac{(1+\alpha) \mathrm{M}}{\mathrm{N}+1+\alpha+\frac{\lambda \mathrm{N}^{2}}{\mathrm{~N}-(1+\alpha)(\mathrm{M}-1)}}
$$

As $(1+\alpha) \mathrm{M}$ is a constant, maximizing $\eta$ is the same as minimizing the denominator:

$$
\gamma=\mathrm{N}+1+\alpha+\frac{\lambda \mathrm{N}^{2}}{\mathrm{~N}-(1+\alpha)(\mathrm{M}-1)},
$$

and $\mathrm{d} \gamma / \mathrm{dN}=0$ is satisfied if

$$
\mathrm{N}_{\mathrm{opt}}=(1+\alpha)\left(1+\sqrt{\frac{\lambda}{1+\lambda}}\right)(\mathrm{M}-1) .
$$

Note that if $\alpha=0$, then (44) is reduced to

$$
\left.\mathrm{N}_{\mathrm{opt}}\right|_{\alpha=0}=\left(1+\sqrt{\frac{\beta}{1+\beta}}\right)(\mathrm{M}-1)
$$

which gives the same result as obtained in [5]. The design strategy according to the above analysis will be discussed in details in Section 10.

\section{$5 \quad$ Analysis of Dual-Branch Linear Charge Pumps}

Dual-branch and multi-phase charge pumps result in smaller output voltage ripples than single-branch counterparts, and in-depth analysis is needed to obtain the design equations $[13,16]$. Fig. 5 shows the schematic of a dual-branch $(\mathrm{N}+1) \mathrm{X}$ linear charge pump, with the two branches operating in complementary phases. Only the charging and discharging phases of Branch $\mathrm{A}$ are labeled. Due to symmetry, we assign $\mathrm{C}_{\mathrm{Ak}}=\mathrm{C}_{\mathrm{Bk}}=\mathrm{C}_{\mathrm{k}}$, but we still use $\mathrm{C}_{\mathrm{Ak}}$ and $\mathrm{C}_{\mathrm{Bk}}$ when clarity in description is needed. 


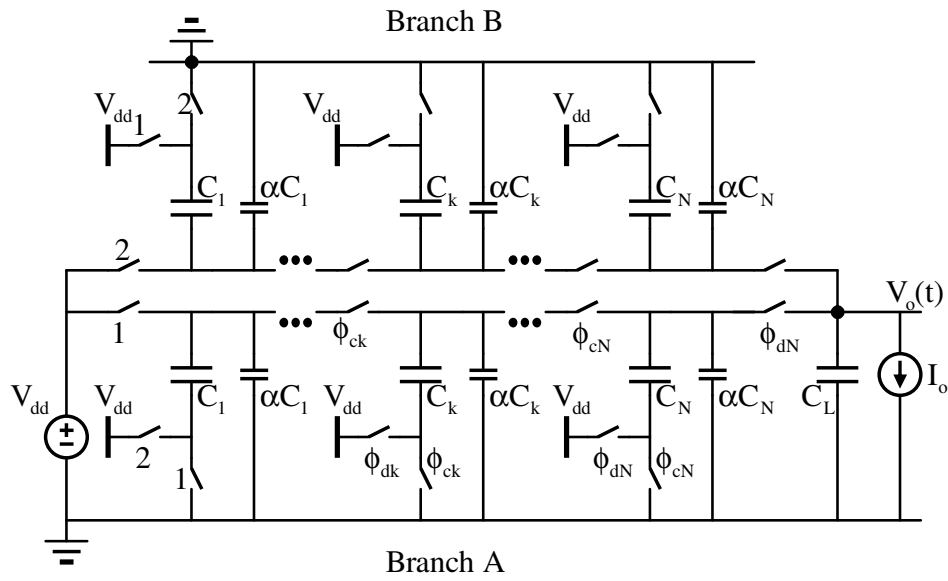

Fig. 5. Dual-branch $(\mathrm{N}+1) \mathrm{X}$ linear charge pump

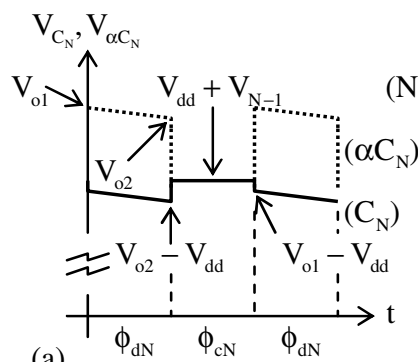

(a)

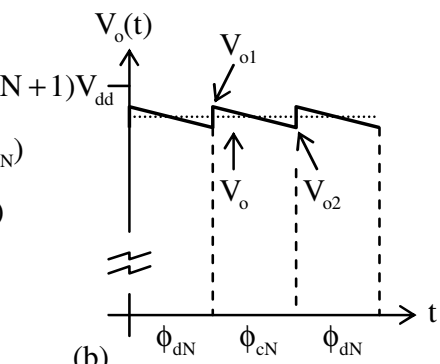

(b)

Fig. 6. Timing diagram of dual-branch LQP of (a) $C_{N}$; and (b) $V_{o}(t)$

Negative-plate parasitic capacitors are not shown. Fig. 6 shows the timing diagrams of $\mathrm{C}_{\mathrm{N}}$ and $\mathrm{V}_{\mathrm{o}}(\mathrm{t})$, as those of $\mathrm{C}_{1}$ and $\mathrm{C}_{\mathrm{k}}$ are the same as the single-branch case.

The analysis follows closely that of the single-branch case and is skipped. The key results of $\mathrm{V}_{\mathrm{o} 1}, \mathrm{~V}_{\mathrm{o} 2}$ and the average output voltage $\mathrm{V}_{\mathrm{o}}=\left(\mathrm{V}_{\mathrm{o} 1}+\mathrm{V}_{\mathrm{o} 2}\right) / 2$ are shown below:

$$
\begin{gathered}
\mathrm{V}_{\mathrm{o} 1}=\frac{\mathrm{N}+1+\alpha}{1+\alpha} \mathrm{V}_{\mathrm{dd}}-\sum_{\mathrm{k}=1}^{\mathrm{N}} \frac{\mathrm{I}_{\mathrm{o}} \mathrm{T} / 2}{(1+\alpha) \mathrm{C}_{\mathrm{k}}}+\frac{\mathrm{I}_{\mathrm{o}} \mathrm{T} / 2}{(1+\alpha) \mathrm{C}_{\mathrm{N}}+\mathrm{C}_{\mathrm{L}}}, \\
\mathrm{V}_{\mathrm{o} 2}=\frac{\mathrm{N}+1+\alpha}{1+\alpha} \mathrm{V}_{\mathrm{dd}}-\sum_{\mathrm{k}=1}^{\mathrm{N}} \frac{\mathrm{I}_{\mathrm{o}} \mathrm{T} / 2}{(1+\alpha) \mathrm{C}_{\mathrm{k}}}, \\
\mathrm{V}_{\mathrm{o}}=\frac{\mathrm{N}+1+\alpha}{1+\alpha} \mathrm{V}_{\mathrm{dd}}-\sum_{\mathrm{k}=1}^{\mathrm{N}} \frac{\mathrm{I}_{\mathrm{o}} \mathrm{T} / 2}{(1+\alpha) \mathrm{C}_{\mathrm{k}}}+\frac{\mathrm{I}_{\mathrm{o}} \mathrm{T} / 4}{(1+\alpha) \mathrm{C}_{\mathrm{N}}+\mathrm{C}_{\mathrm{L}}} .
\end{gathered}
$$


Note again that $V_{o 2}$ is independent of $C_{L}$. For $C_{L}>>C_{k}$, the average output voltage $V_{o}$ is equal to $\mathrm{V}_{\mathrm{o} 2}$, and to maximize $\mathrm{V}_{\mathrm{o} 2}$ and minimize the total capacitance $\mathrm{C}_{\mathrm{T}}$ it is clear that all $\mathrm{C}_{\mathrm{k}}$ should be set equal:

$$
\mathrm{C}_{1}=\mathrm{C}_{2}=\ldots=\mathrm{C}_{\mathrm{N}}=\mathrm{C}_{\mathrm{II}} \text {, }
$$

where the subscript II is for the dual-branch case. The output voltage with $C_{L}>>C_{k}$ is

$$
\mathrm{V}_{\mathrm{o}}=\frac{\mathrm{N}+1+\alpha}{1+\alpha} \mathrm{V}_{\mathrm{dd}}-\frac{\mathrm{NI}_{\mathrm{o}} \mathrm{T} / 2}{(1+\alpha) \mathrm{C}_{\mathrm{II}}},
$$

and the output voltage ripple by restating a finite $C_{L}\left(>C_{k}\right)$ is

$$
\Delta \mathrm{V}_{\mathrm{o}}=\frac{\mathrm{I}_{\mathrm{o}} \mathrm{T}}{2 \mathrm{C}_{\mathrm{L}}}
$$

As in Section 3, if we assign the reduction factor $\delta_{\text {II }}$ as

$$
\delta_{\text {II }}=\frac{\mathrm{I}_{\mathrm{o}} \mathrm{T}}{\mathrm{C}_{\mathrm{II}} \mathrm{V}_{\mathrm{dd}}}=\frac{\mathrm{I}_{\mathrm{o}} \mathrm{T}}{(\mathrm{C} / 2) \mathrm{V}_{\mathrm{dd}}}=2 \delta,
$$

then the voltage conversion ratio is

$$
\mathrm{M}_{\mathrm{II}}=\frac{\mathrm{V}_{\mathrm{o}}}{\mathrm{V}_{\mathrm{dd}}}=\frac{\mathrm{N}+1+\alpha-\mathrm{N} \delta_{\mathrm{II}} / 2}{1+\alpha} .
$$

Compare (50) and (19), if we assign

$$
\mathrm{C}_{\mathrm{II}}=\mathrm{C} / 2
$$

then both single-branch and dual-branch charge pumps have the same output voltage $\mathrm{V}_{\mathrm{o}}$ for the same total capacitance $\mathrm{C}_{\mathrm{T}}$ (note that $2 \mathrm{NC}_{\mathrm{II}}=\mathrm{NC}$ for the dual-branch $\mathrm{LQP}$ ). The only difference between the two LQPs is the output voltage ripple, with the dualbranch LQP being only half of that of the single-branch case. The equation for efficiency of the dual-branch LQP is the same as (35) by replacing $\delta$ with $\delta_{\text {II }} / 2$, and therefore, all equations (36) through (45) apply to both the single-branch and dualbranch linear charge pumps.

\section{Comparison of Single- and Dual-Branch Linear Charge Pumps}

We validate the analyses of single- and dual-branch linear charge pumps for the following aspects. (A) Perform time-domain Cadence simulation to verify equations $(5,13-15)$ of the single-branch LQP, and equations (46-48) of the dual-branch LQP. (B) Perform Cadence simulations on output voltage and efficiency of (A) and compare with theoretical results. (C) Perform Matlab simulation of $\delta_{\text {opt }}$ and $\eta_{\max }$ for different $\mathrm{N}, \alpha$ and $\beta$. Cadence simulations will be performed and compared with 
theoretical values. For all Cadence simulations presented in this paper, the switches are realized by nearly ideal switches that have very low on-resistance of $0.1 \Omega$ and very large off-resistance of $1 \mathrm{~T} \Omega$. Simulations are performed using relative tolerance of $10^{-6}$, absolute tolerance in current of $1 \mathrm{pA}$, and absolute tolerance in voltage of $1 \mu \mathrm{V}$.

(A) For time-domain simulation, we design single-branch and dual-branch 8X LQPs $(\mathrm{N}=7)$ with the following specification: the input voltage $V_{d d}$ is $1 \mathrm{~V}$, the load current $I_{o}$ is $10 \mu \mathrm{A}$, and the switching frequency $\mathrm{f}_{\mathrm{s}}$ is $10 \mathrm{MHz}$. The positive-plate and negativeplate parameters are $\alpha=0.01$ and $\beta=0.05$, respectively. The non-overlapping dead time is set to be $1 \mathrm{~ns}$.

For the single-branch $8 \mathrm{X}$ LQP, we set $\mathrm{C}=20 \mathrm{pF}$ and $\mathrm{C}_{\mathrm{L}}=25 \mathrm{pF}$. Fig. 7(a) shows the simulation result of $\mathrm{V}_{\mathrm{o}}(\mathrm{t})$ on which $\mathrm{V}_{\mathrm{o} 1}, \mathrm{~V}_{\mathrm{o} 2}$ and $\mathrm{V}_{\mathrm{o} 3}$ are marked. For the dual-branch $8 X$ LQP, we set $\mathrm{C}_{\mathrm{II}}=10 \mathrm{pF}$ and $\mathrm{C}_{\mathrm{L}}=25 \mathrm{pF}$. Fig. 7(b) shows the simulation result of $\mathrm{V}_{\mathrm{o}}(\mathrm{t})$ on which $\mathrm{V}_{\mathrm{o} 1}$ and $\mathrm{V}_{\mathrm{o} 2}$ are marked. Table 1 tabulates the analysis and simulation results along with the percentage errors. The errors for $\mathrm{V}_{\mathrm{oi}}$ 's are due to the switch dead time in our simulation and are all smaller than $0.013 \%$.
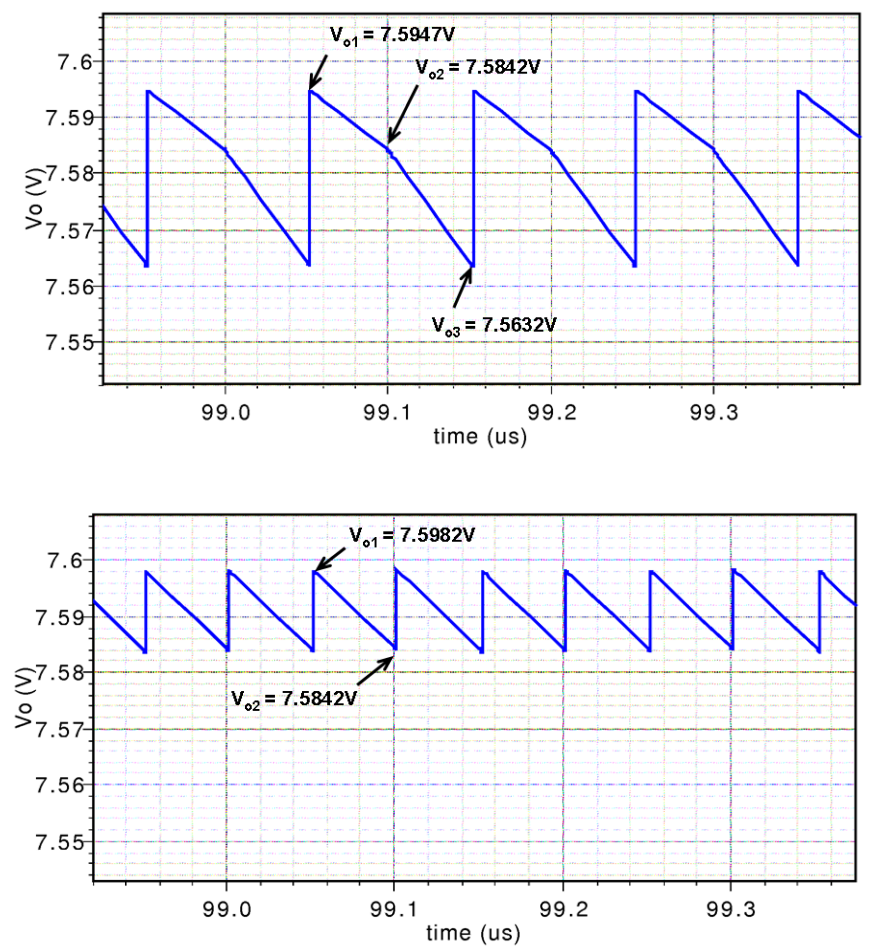

Fig. 7. Time-domain simulation of (a) single-branch LQP; and (b) dual-branch LQP

(B) The reduction factors of the charge pumps in (A) are $\delta=0.05$ and $\delta_{I I}=0.1$, respectively, and are not the optimal values. Efficiency computations are performed 
for $\mathrm{C}_{\mathrm{L}}=25 \mathrm{pF}$ and $\mathrm{C}_{\mathrm{L}}=1 \mathrm{nF}$ (such that it can be regarded as infinite), and both are only around $46.5 \%$ (Table 2). Next, for the single-branch charge pump with $\mathrm{N}=7, \alpha=0.01$, $\beta=0.05$ and $C_{L}=1 \mathrm{nF}, \delta_{\text {opt }}$ is computed from (39) to be 0.1987 and $\eta_{\max }$ is $65.27 \%$. Cadence simulation gives an almost identical efficiency of $65.29 \%$. The results are again tabulated in Table 2.

(C) We would like to find out the general range of $\delta_{\text {opt }}$ and the corresponding $\eta_{\max }$. Fig. 8 shows $\delta_{\text {opt }}$ and $\eta_{\max }$ vs $\alpha, \beta$ and $N$. The negative-plate parasitic parameter $\beta$ takes the value of $0.00,0.05$ and 0.10 , while the positive-plate parasitic parameter $\alpha$ ranges from 0.00 to 0.10 for $\mathrm{N}=1$ (voltage doubler), $\mathrm{N}=3$ and $\mathrm{N}=7$. Cadence simulations are also performed for $\alpha=0$ to $\alpha=0.10$ at an interval of 0.02 . The theoretical curves match very well with Cadence simulations.

Table 1. Output voltages and output voltage ripples of LQPs

\begin{tabular}{|c|c|c|c|}
\hline & Analysis & Simulation & \% error \\
\hline Single-branch & & & \\
\hline $\mathrm{V}_{\mathrm{o} 1}$ & $7.5952 \mathrm{~V}$ & $7.59470 \mathrm{~V}$ & $0.006 \%$ \\
\hline $\mathrm{V}_{\mathrm{o} 2}$ & $7.5842 \mathrm{~V}$ & $7.58419 \mathrm{~V}$ & $0.0001 \%$ \\
\hline $\mathrm{V}_{\mathrm{o} 3}$ & $7.5642 \mathrm{~V}$ & $7.56319 \mathrm{~V}$ & $0.013 \%$ \\
\hline$\Delta \mathrm{V}_{\mathrm{o}}$ & $31.1 \mathrm{mV}$ & $31.5 \mathrm{mV}$ & $1.29 \%$ \\
\hline Dual-branch & & & \\
\hline $\mathrm{V}_{\mathrm{o} 1}$ & $7.5984 \mathrm{~V}$ & $7.5982 \mathrm{~V}$ & $0.0026 \%$ \\
\hline $\mathrm{V}_{\mathrm{o} 2}$ & $7.5842 \mathrm{~V}$ & $7.5835 \mathrm{~V}$ & $0.0092 \%$ \\
\hline$\Delta \mathrm{V}_{\mathrm{o}}$ & $14.2 \mathrm{mV}$ & $14.7 \mathrm{mV}$ & $3.52 \%$ \\
\hline
\end{tabular}

Table 2. Output voltages and efficiencies of LQPs

\begin{tabular}{|c|c|c|c|}
\hline & Analysis & Simulation & $\%$ error \\
\hline \multicolumn{4}{|c|}{ Single-branch with $\delta=0.05, \mathrm{C}=20 \mathrm{pF}, \mathrm{C}_{\mathrm{L}}=25 \mathrm{pF}$} \\
\hline $\mathrm{V}_{\mathrm{o}}$ & $7.5820 \mathrm{~V}$ & $7.5816 \mathrm{~V}$ & $0.0053 \%$ \\
\hline$\eta$ & $46.47 \%$ & $46.49 \%$ & $0.043 \%$ \\
\hline \multicolumn{4}{|c|}{ Single-branch with $\delta=0.05, \mathrm{C}=20 \mathrm{pF}, \mathrm{C}_{\mathrm{L}}=1 \mathrm{nF}$} \\
\hline $\mathrm{V}_{\mathrm{o}}$ & $7.5842 \mathrm{~V}$ & $7.5841 \mathrm{~V}$ & $0.0013 \%$ \\
\hline$\eta$ & $46.48 \%$ & $46.51 \%$ & $0.065 \%$ \\
\hline \multicolumn{4}{|c|}{ Dual-branch with $\delta_{\mathrm{II}}=0.1, \mathrm{C}_{\mathrm{II}}=10 \mathrm{pF}, \mathrm{C}_{\mathrm{L}}=25 \mathrm{pF}$} \\
\hline $\mathrm{V}_{0}$ & $7.5913 \mathrm{~V}$ & $7.5909 \mathrm{~V}$ & $0.0053 \%$ \\
\hline$\eta$ & $46.52 \%$ & $46.54 \%$ & $0.043 \%$ \\
\hline \multicolumn{4}{|c|}{ Dual-branch with $\delta_{\mathrm{II}}=0.1, \mathrm{C}_{\mathrm{II}}=10 \mathrm{pF}, \mathrm{C}_{\mathrm{L}}=1 \mathrm{nF}$} \\
\hline $\mathrm{V}_{\mathrm{o}}$ & $7.5844 \mathrm{~V}$ & $7.5843 \mathrm{~V}$ & $0.0013 \%$ \\
\hline$\eta$ & $46.48 \%$ & $46.50 \%$ & $0.043 \%$ \\
\hline \multicolumn{4}{|c|}{ Single-branch with $\delta_{\text {opt }}=0.1987, C=5.032 p F, C_{L}=1 \mathrm{nF}$} \\
\hline $\mathrm{V}_{\mathrm{o}}$ & $6.5535 \mathrm{~V}$ & $6.5534 \mathrm{~V}$ & $0.0015 \%$ \\
\hline$\eta$ & $65.27 \%$ & $65.29 \%$ & $0.031 \%$ \\
\hline
\end{tabular}




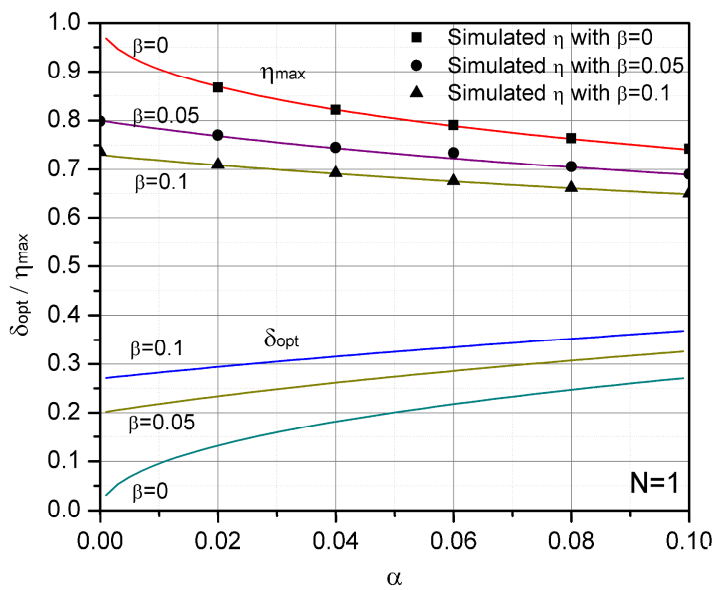

(a)

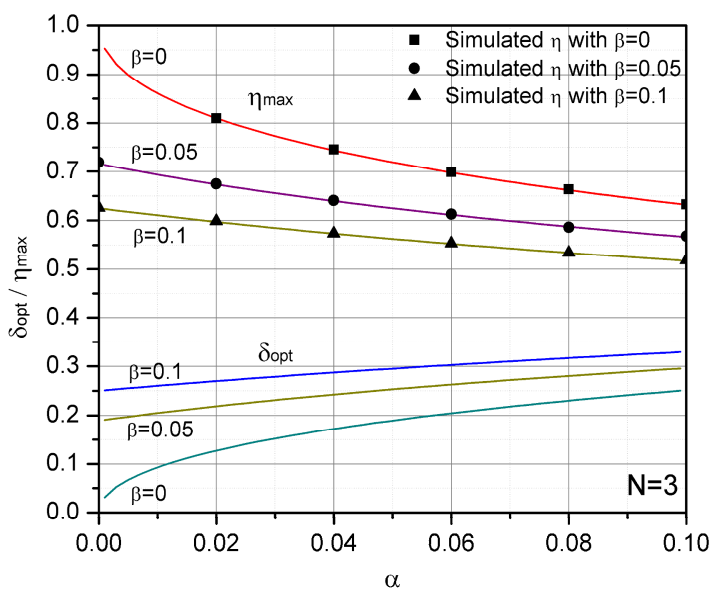

(b)

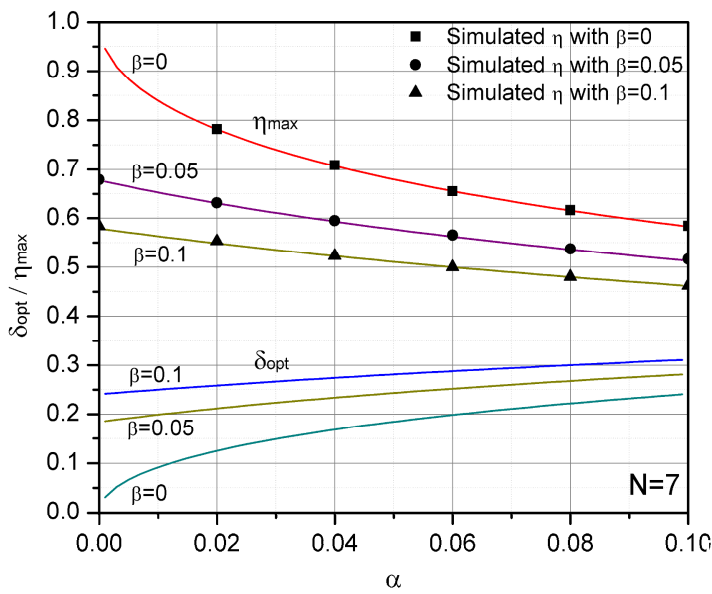

(c)

Fig. 8. $\delta$ opt and $\eta_{\max }$ for (a) $\mathrm{N}=1$; (b) $\mathrm{N}=3$; and (c) $\mathrm{N}=7$ 


\section{$7 \quad$ Analysis of Fibonacci Charge Pumps}

Fig. 9 shows a single-branch $8 \mathrm{X}$ Fibonacci charge pump, leaving out all parasitic capacitors for a clear exposition of the topology [9]. It uses only four flying capacitors to achieve a voltage conversion ratio of 8 . An immediate question is: will the total capacitance be smaller than that of the $8 \mathrm{X}$ LQP for the same output voltage $\mathrm{V}_{\mathrm{o}}$ ? In fact, the same question can be asked of the $8 \mathrm{X}$ exponential charge pump to be discussed in Section 8. For a complete analysis with $\mathrm{C}_{\mathrm{L}} \neq 0$ including parasitic capacitors, it can be shown, by following the procedure as discussed in Section 3, that $\mathrm{V}_{\mathrm{O} 2}$ of both single- and dual-branch charge pumps are independent of $\mathrm{C}_{\mathrm{L}}$, and as $\mathrm{C}_{\mathrm{L}} \rightarrow \infty, \mathrm{V}_{\mathrm{o}} \rightarrow \mathrm{V}_{\mathrm{o} 2}$. Therefore, we assume $\mathrm{C}_{\mathrm{L}}=\infty$ to arrive at a simpler procedure as discussed below.

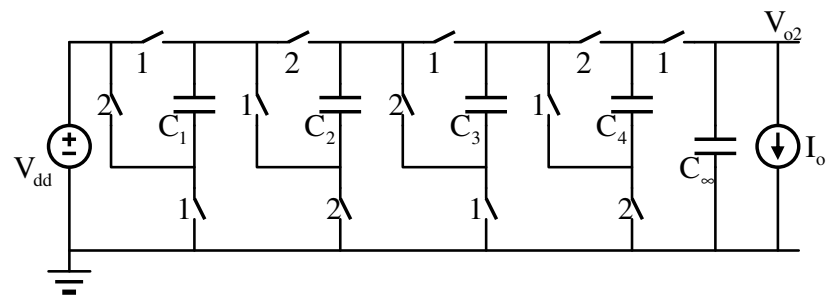

Fig. 9. Single-branch $8 X$ Fibonacci charge pump

Fig. 10 shows the connections of the switches, the flying capacitors and their parasitic capacitors of the 8X FQP in both $\phi_{1}=1$ and $\phi_{2}=1$. As discussed in Section 3, for any flying capacitor $C_{k}$, the charging phase is $\phi_{\mathrm{ck}}$ and the discharging phase is $\phi_{\mathrm{dk}}$, and the capacitor voltage when fully discharged in $\phi_{\mathrm{dk}}=1$ is designated as $\mathrm{V}_{\mathrm{k}}$. Clearly, in $\phi_{\mathrm{c} 1}=\phi_{1}=1, \mathrm{C}_{1}$ is charged to $\mathrm{V}_{\mathrm{dd}}$, and in $\phi_{\mathrm{d} 1}=\phi_{2}=1, \mathrm{C}_{1}$ is discharged to $\mathrm{V}_{1}$, but then $\phi_{\mathrm{d} 1}$ is the same as $\phi_{\mathrm{c} 2}$, and $\mathrm{C}_{2}$ is charged to $\mathrm{V}_{\mathrm{dd}}+\mathrm{V}_{1}$. The same mechanism propagates down the stages, and it also applies to the parasitic capacitors. Let us consider the case with $\alpha=\beta=0$ first. It is straightforward to work from the last stage back to the first stage. In the charging phase of $C_{4}$ (i.e., $\phi_{2}=1$ ), $C_{4}$ is charged to $V_{d d}+V_{1}+V_{3}$, while $C_{\infty}$ is discharged by $\mathrm{I}_{0}$ for the duration of $T / 2$. In the discharging phase, $\mathrm{C}_{4}$ is stacked on top of $V_{d d}$ and $C_{2}$, and $C_{4}$ supports $I_{o}$ for $T / 2$, and $C_{4}$ is eventually discharged to $V_{4}$. Employ QBL, we have

$$
\mathrm{C}_{4}\left(\mathrm{~V}_{\mathrm{dd}}+\mathrm{V}_{1}+\mathrm{V}_{3}\right)=\mathrm{C}_{4} \mathrm{~V}_{4}+\mathrm{I}_{\mathrm{o}} \mathrm{T}
$$

Note that for $\mathrm{C}_{\mathrm{L}}=\mathrm{C}_{\infty}=\infty$, the output voltage $\mathrm{V}_{\mathrm{o} 2}$ will never change, and we need to account for the load current consumption as discussed above so that the result would be correct. Next, for charge transfer at $\mathrm{V}_{\mathrm{d}}\left(\phi_{1} \rightarrow \phi_{2}\right)$, we have

$$
\mathrm{C}_{3}\left(\mathrm{~V}_{\mathrm{dd}}+\mathrm{V}_{2}\right)+\mathrm{C}_{4} \mathrm{~V}_{4}=\mathrm{C}_{3} \mathrm{~V}_{3}+\mathrm{C}_{4}\left(\mathrm{~V}_{\mathrm{dd}}+\mathrm{V}_{1}+\mathrm{V}_{3}\right)
$$

and it can be simplified using the result of (55) to give

$$
\mathrm{C}_{3}\left(\mathrm{~V}_{\mathrm{dd}}+\mathrm{V}_{2}\right)=\mathrm{C}_{3} \mathrm{~V}_{3}+\mathrm{I}_{\mathrm{o}} \mathrm{T} \text {. }
$$


(a) $\phi_{1}=1$

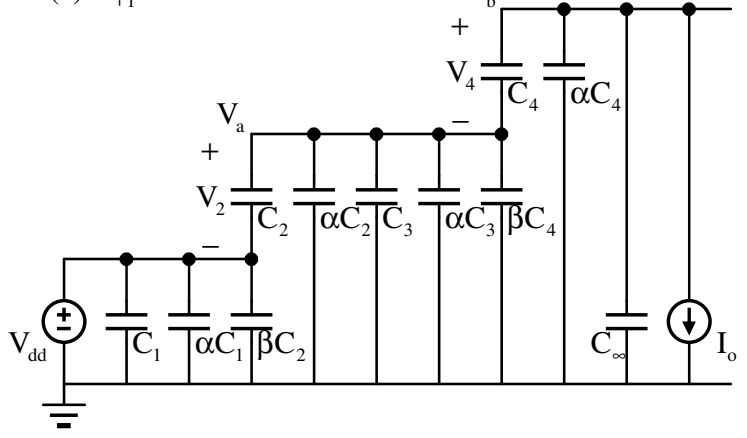

(b) $\phi_{2}=1$

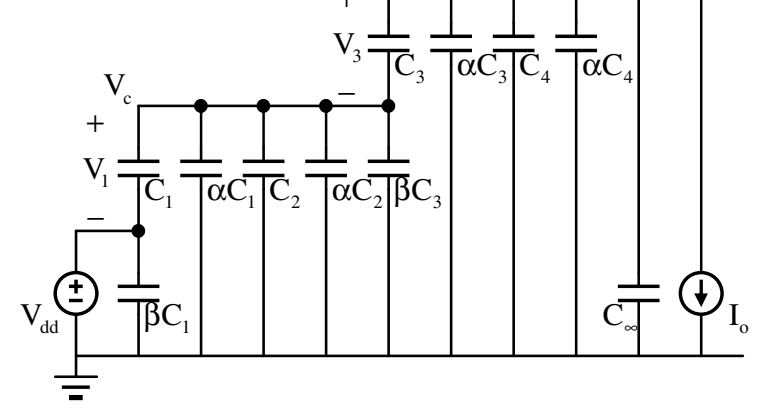

Fig. 10. Capacitor connections of $8 X \mathrm{XQP}$ in (a) $\phi_{1}=1$; and (b) $\phi_{2}=1$

The charge transfer at $\mathrm{V}_{\mathrm{a}}\left(\phi_{2} \rightarrow \phi_{1}\right)$ is not as straightforward, as it is the negative plate of $\mathrm{C}_{4}$ that is connected to $\mathrm{V}_{\mathrm{a}}$. Taking this into consideration and we obtain

$$
\mathrm{C}_{2}\left(\mathrm{~V}_{\mathrm{dd}}+\mathrm{V}_{1}\right)+\mathrm{C}_{3} \mathrm{~V}_{3}-\mathrm{C}_{4}\left(\mathrm{~V}_{\mathrm{dd}}+\mathrm{V}_{1}+\mathrm{V}_{3}\right)=\mathrm{C}_{2} \mathrm{~V}_{2}+\mathrm{C}_{3}\left(\mathrm{~V}_{\mathrm{dd}}+\mathrm{V}_{2}\right)-\mathrm{C}_{4} \mathrm{~V}_{4}
$$

Using both (55) and (57) gives

$$
\mathrm{C}_{2}\left(\mathrm{~V}_{\mathrm{dd}}+\mathrm{V}_{1}\right)=\mathrm{C}_{2} \mathrm{~V}_{2}+\mathrm{I}_{\mathrm{o}} \mathrm{T} .
$$

In a similar fashion, the charge transfer at $\mathrm{V}_{\mathrm{c}}\left(\phi_{1} \rightarrow \phi_{2}\right)$ gives

$$
\mathrm{C}_{1} \mathrm{~V}_{\mathrm{dd}}=\mathrm{C}_{1} \mathrm{~V}_{1}+3 \mathrm{I}_{\mathrm{o}} \mathrm{T} \text {. }
$$

Backward substitution can then be performed, and we obtain

$$
\begin{gathered}
\mathrm{V}_{1}=\mathrm{V}_{\mathrm{dd}}-\frac{3 \mathrm{I}_{\mathrm{o}} \mathrm{T}}{\mathrm{C}_{1}}, \\
\mathrm{~V}_{2}=2 \mathrm{~V}_{\mathrm{dd}}-\frac{3 \mathrm{I}_{\mathrm{o}} \mathrm{T}}{\mathrm{C}_{1}}-\frac{2 \mathrm{I}_{\mathrm{o}} \mathrm{T}}{\mathrm{C}_{2}},
\end{gathered}
$$




$$
\begin{gathered}
\mathrm{V}_{3}=3 \mathrm{~V}_{\mathrm{dd}}-\frac{3 \mathrm{I}_{\mathrm{o}} \mathrm{T}}{\mathrm{C}_{1}}-\frac{2 \mathrm{I}_{\mathrm{o}} \mathrm{T}}{\mathrm{C}_{2}}-\frac{\mathrm{I}_{\mathrm{o}} \mathrm{T}}{\mathrm{C}_{3}}, \\
\mathrm{~V}_{4}=5 \mathrm{~V}_{\mathrm{dd}}-\frac{3 \mathrm{I}_{\mathrm{o}} \mathrm{T}}{\mathrm{C}_{1}}-\frac{2 \mathrm{I}_{\mathrm{o}} \mathrm{T}}{\mathrm{C}_{2}}-\frac{\mathrm{I}_{\mathrm{o}} \mathrm{T}}{\mathrm{C}_{3}}-\frac{\mathrm{I}_{\mathrm{o}} \mathrm{T}}{\mathrm{C}_{4}} .
\end{gathered}
$$

Finally, $\mathrm{V}_{\mathrm{o} 2}=\mathrm{V}_{\mathrm{dd}}+\mathrm{V}_{2}+\mathrm{V}_{4}$, and we have

$$
\mathrm{V}_{\mathrm{o} 2}=8 \mathrm{~V}_{\mathrm{dd}}-\frac{9 \mathrm{I}_{\mathrm{o}} \mathrm{T}}{\mathrm{C}_{1}}-\frac{4 \mathrm{I}_{\mathrm{o}} \mathrm{T}}{\mathrm{C}_{2}}-\frac{\mathrm{I}_{\mathrm{o}} \mathrm{T}}{\mathrm{C}_{3}}-\frac{\mathrm{I}_{\mathrm{o}} \mathrm{T}}{\mathrm{C}_{4}} .
$$

The analysis of a higher order FQP is similar, and one can easily infer the result from observing the above trend of $\mathrm{V}_{\mathrm{k}}$. From (65), it is obvious that the capacitors should not have the same value: the $1 / C_{1}$ term has a weight of 9 , the $1 / C_{2}$ term has a weight of 4 , and the $1 / C_{3}$ and $1 / C_{4}$ terms have weights of 1 . Qualitatively, $C_{1}$ should be larger to minimize the reduction due to a larger weight. Quantitatively, to minimize the total capacitance, the procedure described in $[1,13]$ should be followed, and the optimal assignment is

$$
\begin{gathered}
\mathrm{C}_{1}=3 \mathrm{C}, \\
\mathrm{C}_{2}=2 \mathrm{C}, \\
\mathrm{C}_{3}=\mathrm{C}_{4}=\mathrm{C}, \\
\mathrm{C}_{\mathrm{T}}=\mathrm{C}_{1}+\mathrm{C}_{2}+\mathrm{C}_{3}+\mathrm{C}_{4}=7 \mathrm{C} .
\end{gathered}
$$

Using the above optimal assignment for the ideal case, we have

$$
\mathrm{V}_{\mathrm{o} 2}=8 \mathrm{~V}_{\mathrm{dd}}-\frac{7 \mathrm{I}_{\mathrm{o}} \mathrm{T}}{\mathrm{C}}
$$

This is the same result as obtained for the single-branch 8X LQP with $\alpha=0$ (19). Therefore, for on-chip implementation, there is no advantage in saving capacitor area by using FQP instead of LQP. This is a very important conclusion of this research. Nevertheless, we continue to work out the voltage conversion ratio in the presence of $\alpha C_{k}$ and $\beta C_{k}$, as the result would be useful for off-chip implementation.

In analyzing $\mathrm{FQP}$ including $\alpha \mathrm{C}_{\mathrm{k}}$ and $\beta \mathrm{C}_{\mathrm{k}}$, we propose a first iteration approximation (FIA) analysis. This procedure can work with both $\alpha C_{k}$ and $\beta C_{k}$ together, but for the purpose of illustration, let us consider only $\alpha C_{k}$ first $(\beta=0)$. Again, we consider the charge transfer at $\mathrm{V}_{\mathrm{b}}\left(\phi_{2} \rightarrow \phi_{1}\right)$ and obtain

$$
(1+\alpha) C_{4}\left(V_{d d}+V_{1}+V_{3}\right)=C_{4} V_{4}+\alpha C_{4}\left(V_{d d}+V_{2}+V_{4}\right)+I_{o} T \text {. }
$$

Eq. (71) can be rearranged to read 


$$
\mathrm{C}_{4}\left(\mathrm{~V}_{\mathrm{dd}}+\mathrm{V}_{1}+\mathrm{V}_{3}\right)=\mathrm{C}_{4} \mathrm{~V}_{4}+\alpha \mathrm{C}_{4}\left(\mathrm{~V}_{4}-\mathrm{V}_{3}+\mathrm{V}_{2}-\mathrm{V}_{1}\right)+\mathrm{I}_{\mathrm{o}} \mathrm{T}
$$

Following the same procedure and rearranging the corresponding equations as in (72), we have

$$
\begin{gathered}
\mathrm{C}_{3}\left(\mathrm{~V}_{\mathrm{dd}}+\mathrm{V}_{2}\right)=\mathrm{C}_{3} \mathrm{~V}_{3}+\alpha \mathrm{C}_{3}\left(\mathrm{~V}_{3}-\mathrm{V}_{2}+\mathrm{V}_{1}\right)+\mathrm{I}_{\mathrm{o}} \mathrm{T} \\
\mathrm{C}_{2}\left(\mathrm{~V}_{\mathrm{dd}}+\mathrm{V}_{1}\right)=\mathrm{C}_{2} \mathrm{~V}_{2}+\alpha \mathrm{C}_{2}\left(\mathrm{~V}_{2}-\mathrm{V}_{1}\right)+\alpha \mathrm{C}_{4}\left(\mathrm{~V}_{4}-\mathrm{V}_{3}+\mathrm{V}_{2}-\mathrm{V}_{1}\right)+2 \mathrm{I}_{\mathrm{o}} \mathrm{T} \\
\mathrm{C}_{1} \mathrm{~V}_{\mathrm{dd}}=\mathrm{C}_{1} \mathrm{~V}_{1}+\alpha \mathrm{C}_{1} \mathrm{~V}_{1}+\alpha \mathrm{C}_{3}\left(\mathrm{~V}_{3}-\mathrm{V}_{2}+\mathrm{V}_{1}\right)+\alpha \mathrm{C}_{4}\left(\mathrm{~V}_{4}-\mathrm{V}_{3}+\mathrm{V}_{2}-\mathrm{V}_{1}\right)+3 \mathrm{I}_{\mathrm{o}} \mathrm{T}
\end{gathered}
$$

The difficulty of solving (72) to (75) lies with the parasitic terms $\alpha \mathrm{C}_{\mathrm{k}}$. Consider (72). If $\alpha$ is very small, the term with $\alpha C_{4}$ should be much smaller than the terms with $\mathrm{C}_{4}$ only. If there is an error in the multiplicand of $\alpha C_{4}$ (that is, $V_{4}-V_{3}+V_{2}-V_{1}$ ), the error would be of second order and can be neglected. Now, for $\alpha, \beta, \delta<<1$, we have $\mathrm{V}_{4} \approx 5 \mathrm{~V}_{\mathrm{dd}}, \mathrm{V}_{3} \approx 3 \mathrm{~V}_{\mathrm{dd}}, \mathrm{V}_{2} \approx 2 \mathrm{~V}_{\mathrm{dd}}$ and $\mathrm{V}_{1} \approx \mathrm{V}_{\mathrm{dd}}$. Using this approximation we have

$$
\alpha \mathrm{C}_{4}\left(\mathrm{~V}_{4}-\mathrm{V}_{3}+\mathrm{V}_{2}-\mathrm{V}_{1}\right) \approx 3 \alpha \mathrm{C}_{4} \mathrm{~V}_{\mathrm{dd}} .
$$

Performing the same approximation for (73), (74) and (75) by also including $\beta \neq 0$ we obtain

$$
\begin{gathered}
\mathrm{V}_{1} \approx \mathrm{V}_{\mathrm{dd}}-\frac{8 \alpha}{3} \mathrm{~V}_{\mathrm{dd}}-\frac{5 \beta}{3} \mathrm{~V}_{\mathrm{dd}}-\frac{\mathrm{I}_{\mathrm{o}} \mathrm{T}}{\mathrm{C}}, \\
\mathrm{V}_{2} \approx 2 \mathrm{~V}_{\mathrm{dd}}-\frac{31 \alpha}{6} \mathrm{~V}_{\mathrm{dd}}-\frac{19 \beta}{6} \mathrm{~V}_{\mathrm{dd}}-\frac{2 \mathrm{I}_{\mathrm{o}} \mathrm{T}}{\mathrm{C}}, \\
\mathrm{V}_{3} \approx 3 \mathrm{~V}_{\mathrm{dd}}-\frac{43 \alpha}{6} \mathrm{~V}_{\mathrm{dd}}-\frac{19 \beta}{6} \mathrm{~V}_{\mathrm{dd}}-\frac{3 \mathrm{I}_{\mathrm{o}} \mathrm{T}}{\mathrm{C}}, \\
\mathrm{V}_{4} \approx 5 \mathrm{~V}_{\mathrm{dd}}-\frac{77 \alpha}{6} \mathrm{~V}_{\mathrm{dd}}-\frac{29 \beta}{6} \mathrm{~V}_{\mathrm{dd}}-\frac{5 \mathrm{I}_{\mathrm{o}} \mathrm{T}}{\mathrm{C}}, \\
\mathrm{V}_{\mathrm{o} 2(\mathrm{FQP})} \approx 8 \mathrm{~V}_{\mathrm{dd}}-18 \alpha \mathrm{V}_{\mathrm{dd}}-8 \beta \mathrm{V}_{\mathrm{dd}}-\frac{7 \mathrm{I}_{\mathrm{o}} \mathrm{T}}{\mathrm{C}} .
\end{gathered}
$$

This output voltage is much lower than that of the LQP (19):

$$
\mathrm{V}_{\mathrm{o} 2(\mathrm{LQP})} \approx 8 \mathrm{~V}_{\mathrm{dd}}-7 \alpha \mathrm{V}_{\mathrm{dd}}-\frac{7 \mathrm{I}_{\mathrm{o}} \mathrm{T}}{\mathrm{C}} \text {. }
$$

Clearly, linear charge pumps are preferred to Fibonacci charge pumps for on-chip implementation. 


\section{Analysis of Exponential Charge Pumps}

Fig. 11 shows the dual-branch exponential charge pump that uses $2 \mathrm{~N}$ flying capacitors and one load capacitor $[10,11]$. Note that with $\mathrm{N}$ flying capacitors, a $2^{\mathrm{N}} \mathrm{X}$ charge pump can only be realized using a multi-phase clock $[17,18]$. The analysis is left as a challenge to the readers and only the key results are presented below. For the optimal capacitor assignment with $\alpha=\beta=0$, we have

$$
\begin{gathered}
\mathrm{C}_{1 \mathrm{~A}}=\mathrm{C}_{1 \mathrm{~B}}=4 \mathrm{C}_{\mathrm{II}}, \\
\mathrm{C}_{2 \mathrm{~A}}=\mathrm{C}_{2 \mathrm{~B}}=2 \mathrm{C}_{\mathrm{II}}, \\
\mathrm{C}_{3 \mathrm{~A}}=\mathrm{C}_{3 \mathrm{~B}}=\mathrm{C}_{\mathrm{II}}, \\
\mathrm{C}_{\mathrm{T}}=2 \times\left(\mathrm{C}_{1 \mathrm{~A}}+\mathrm{C}_{2 \mathrm{~A}}+\mathrm{C}_{3 \mathrm{~A}}\right)=14 \mathrm{C}_{\mathrm{II}} .
\end{gathered}
$$

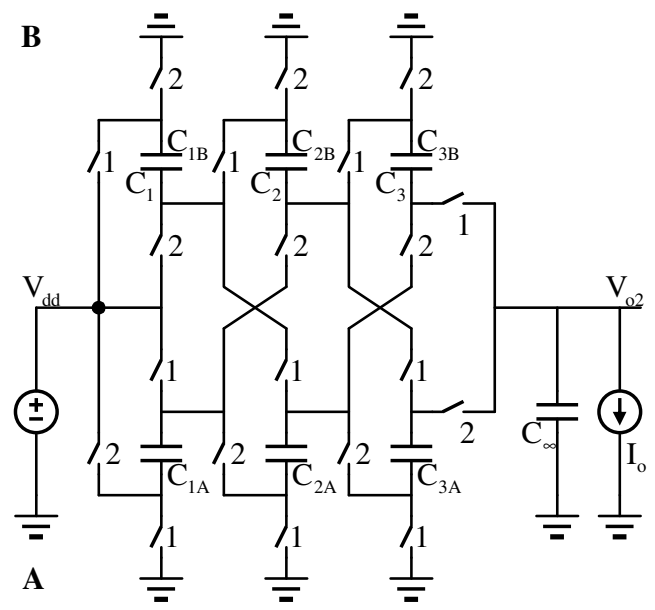

Fig. 11. Dual-branch $8 X$ exponential charge pump

For $\alpha, \beta \neq 0$, we use first iteration approximation and the final capacitor voltages $V_{k}$ and $\mathrm{V}_{\mathrm{o} 2}$ are

$$
\begin{gathered}
\mathrm{V}_{1} \approx \mathrm{V}_{\mathrm{dd}}-4 \alpha \mathrm{V}_{\mathrm{dd}}-3 \beta \mathrm{V}_{\mathrm{dd}}-\frac{\mathrm{I}_{\mathrm{o}} \mathrm{T}}{2 \mathrm{C}_{\mathrm{II}}}, \\
\mathrm{V}_{2} \approx 2 \mathrm{~V}_{\mathrm{dd}}-8 \alpha \mathrm{V}_{\mathrm{dd}}-5 \beta \mathrm{V}_{\mathrm{dd}}-\frac{\mathrm{I}_{\mathrm{o}} \mathrm{T}}{\mathrm{C}_{\mathrm{II}}}, \\
\mathrm{V}_{3} \approx 4 \mathrm{~V}_{\mathrm{dd}}-16 \alpha \mathrm{V}_{\mathrm{dd}}-8 \beta \mathrm{V}_{\mathrm{dd}}-\frac{2 \mathrm{I}_{\mathrm{o}} \mathrm{T}}{\mathrm{C}_{\mathrm{II}}},
\end{gathered}
$$




$$
\mathrm{V}_{\mathrm{o} 2(\mathrm{EQP})} \approx 8 \mathrm{~V}_{\mathrm{dd}}-28 \alpha \mathrm{V}_{\mathrm{dd}}-16 \beta \mathrm{V}_{\mathrm{dd}}-\frac{7 \mathrm{I}_{\mathrm{o}} \mathrm{T}}{2 \mathrm{C}_{\mathrm{II}}} \text {. }
$$

This result is to be compared with (81) and (82) for $\alpha=\beta=0$ : with $C_{I I}=C / 2$, all LQP, FQP and EQP have the same output voltage using the same total capacitance. For the same $\alpha \neq 0$ and/or $\beta \neq 0$, LQP achieves the highest voltage conversion ratio, and EQP achieves the lowest voltage conversion ratio.

\section{Comparison of LQPs, FQPs and EQPs}

For the purpose of comparison, we design single-branch 8X LQP and 8X FQP, and dual-branch $8 \mathrm{X}$ LPQ, 8X FQP and $8 \mathrm{X}$ EQP with the following specification: the input voltage $V_{d d}$ is $1 \mathrm{~V}$, the load current $I_{o}$ is $10 \mu \mathrm{A}$, and the switching frequency $\mathrm{f}_{\mathrm{s}}$ is $10 \mathrm{MHz}$. Ideal switches are used and the non-overlapping dead time is set to be $1 \mathrm{~ns}$. The single-branch unit capacitor $\mathrm{C}_{(1 \mathrm{~B})}=\mathrm{C}$ is $20 \mathrm{pF}$, such that the reduction factor $\delta=$ $\mathrm{I}_{\mathrm{o}} \mathrm{T} /\left(\mathrm{CV}_{\mathrm{dd}}\right)$ is 0.05 , and the total capacitance of all charge pumps are $\mathrm{C}_{\mathrm{T}}=140 \mathrm{pF}$. The load capacitor $C_{L}$ is $1 n F$ to fulfill the assumption of $C_{L}>>C_{k}$. Due to limited space, only the time-domain simulation of the single-branch $8 \mathrm{X}$ FQP is shown. Fig. 12 shows the positive-plate voltages of $\mathrm{C}_{\mathrm{k}}$ and the output voltage $\mathrm{V}_{\mathrm{o}}(\mathrm{t})$ for the case with $\alpha=0.025$ and $\beta=0.04$. As $C_{L} \neq \infty, V_{o}(t)$ is not a constant; but the mid-voltage of $V_{o}(t)$ is $\mathrm{V}_{\mathrm{o} 2}$ as shown.

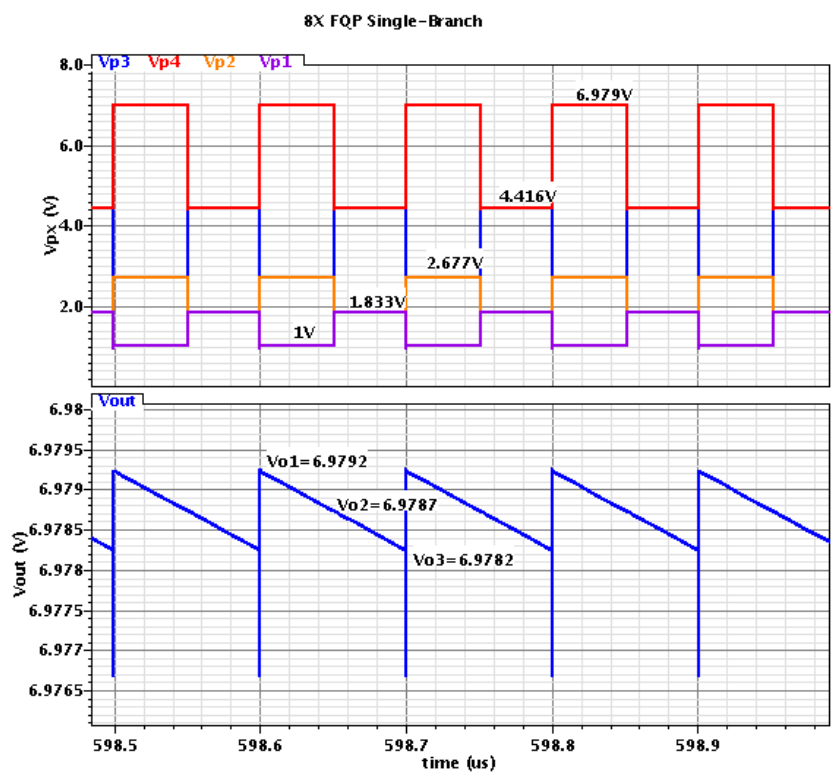

Fig. 12. Simulated waveforms of single-branch $8 X$ FQP 
The simulated values are to be compared with the computed values using FIA analysis. Consider the positive-plate voltage of $\mathrm{C}_{4}$. The maximum value (in the discharging phase) is $6.979 \mathrm{~V}$, and the minimum value (in the charging phase) is $2.677 \mathrm{~V}$. Hence, $\mathrm{V}_{4(\mathrm{sim})}=6.979-2.677=4.302 \mathrm{~V}$. The curves are a little bit difficult to read due to overlapping. Eq. (81) gives $\mathrm{V}_{4 \text { (comp) }}=4.236 \mathrm{~V}$, and the error is $-1.6 \%$. The computed and simulated values are compiled in Table 3. Note that in FIA analysis, $\mathrm{V}_{\mathrm{k}}$ in the $\alpha \mathrm{C}_{\mathrm{k}}$ terms are over-estimated, and they lead to consistently under estimation of the computed $\mathrm{V}_{\mathrm{k}}$ terms.

Fig. 13 shows the time-domain simulation of the dual-branch $8 X \mathrm{XQP}$ with $\mathrm{C}_{(2 \mathrm{~B})}=$ $\mathrm{C}_{\mathrm{II}}=\mathrm{C} / 2=10 \mathrm{pF}$, such that $\mathrm{C}_{\mathrm{T}}=140 \mathrm{pF}$. Except for the reduction in output voltage ripple as discussed in [13], the corresponding voltages of the dual-branch FQP are the same as the single-branch counterpart, verifying our conclusion that they should have the same performance when $\mathrm{C}_{\mathrm{L}}=\infty$.

The second set of simulations is to plot the output voltage $V_{\mathrm{o} 2}$ vs $\alpha$ and $V_{\mathrm{o} 2}$ vs $\beta$ individually. Here, all three charge pumps are dual-branch charge pumps. Optimal capacitance assignment for the respective ideal case is used. Hence, for the $8 \mathrm{X} \mathrm{LQP}, \mathrm{C}_{\mathrm{kA}}=\mathrm{C}_{\mathrm{kB}}=\mathrm{C}=10 \mathrm{pF}$, where the subscript "A" is for the Abranch, and "B" for the B-branch. For the $8 X$ FQP, $C_{1 A}: C_{2 A}: C_{3 A}: C_{4 A}=$ $\mathrm{C}_{1 \mathrm{~B}}: \mathrm{C}_{2 \mathrm{~B}}: \mathrm{C}_{3 \mathrm{~B}}: \mathrm{C}_{4 \mathrm{~B}}=3 \mathrm{C}: 2 \mathrm{C}: \mathrm{C}: \mathrm{C}$; and for the 8X EQP, $\mathrm{C}_{1 \mathrm{~A}}: \mathrm{C}_{2 \mathrm{~A}}: \mathrm{C}_{3 \mathrm{~A}}=\mathrm{C}_{1 \mathrm{~B}}: \mathrm{C}_{2 \mathrm{~B}}: \mathrm{C}_{3 \mathrm{~B}}=$ $4 \mathrm{C}: 2 \mathrm{C}: \mathrm{C}$. For all three charge pumps, the total on-chip capacitance $\mathrm{C}_{\mathrm{T}}$ is $140 \mathrm{pF}$, and $\mathrm{C}_{\mathrm{L}}=1 \mathrm{nF}$.

Fig. 14 shows the simulation results of $\mathrm{V}_{\mathrm{o} 2}$ vs $\alpha$ and $\mathrm{V}_{\mathrm{o} 2}$ vs $\beta$ for all three charge pumps, with both $\alpha$ and $\beta$ changed from 0 to 0.1 . The calculated results match the simulated results quite well when $\alpha$ and $\beta$ are small, as shown in Table 3: for $\alpha=0.025$ and $\beta=0.04$, the error is only $-1.4 \%$. The differences become larger for larger $\alpha$ and $\beta$. To enhance the accuracy in computation, a more complicated second iteration approximation has to be used.

Table 3. Computed and Simulated values of $8 \mathrm{X}$ FQP

\begin{tabular}{|c|r|c|c|}
\hline & \multicolumn{1}{|c|}{ Computed } & \multicolumn{1}{c|}{ Simulated } & Error \\
\hline $\mathrm{V}_{1}$ & $0.817 \mathrm{~V}$ & $1.833-1.000=0.833 \mathrm{~V}$ & $-2.0 \%$ \\
\hline $\mathrm{V}_{2}$ & $1.644 \mathrm{~V}$ & $2.677-1.000=1.677 \mathrm{~V}$ & $-2.0 \%$ \\
\hline $\mathrm{V}_{3}$ & $2.544 \mathrm{~V}$ & $4.416-1.833=2.583 \mathrm{~V}$ & $-1.5 \%$ \\
\hline $\mathrm{V}_{4}$ & $4.236 \mathrm{~V}$ & $6.979-2.677=4.302 \mathrm{~V}$ & $-1.6 \%$ \\
\hline $\mathrm{V}_{02}$ & $6.880 \mathrm{~V}$ & $6.979 \mathrm{~V}$ & $-1.4 \%$ \\
\hline
\end{tabular}




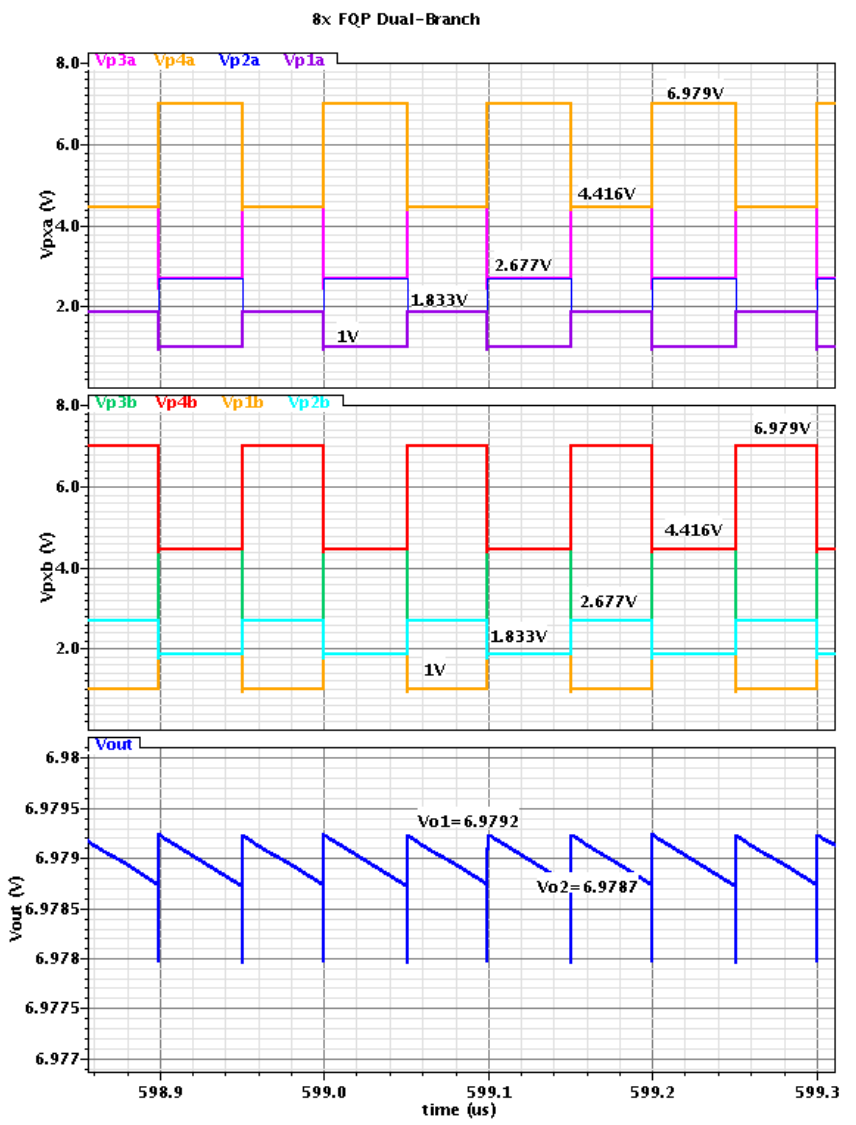

Fig. 13. Simulated waveforms of dual branch $8 \mathrm{X}$ FQP

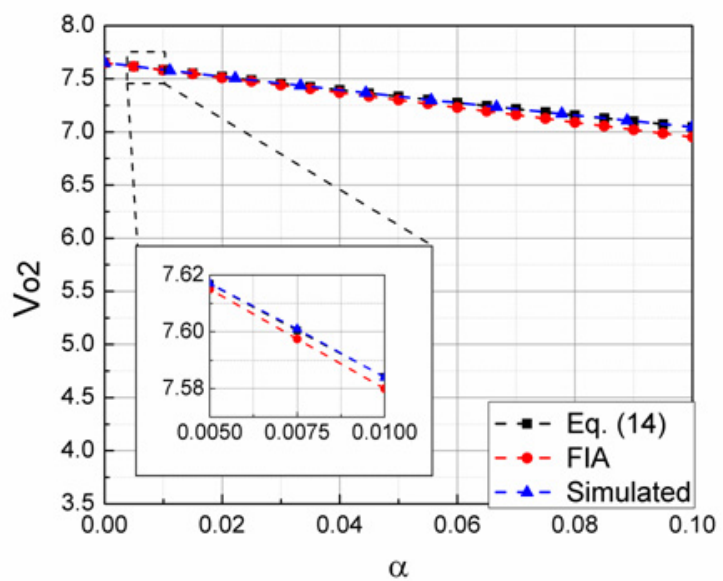

Fig. 14. Vo2 vs $\alpha$ and $V_{o 2}$ vs $\beta$ for (a) LQP; (b) FQP; and (c) EQP 

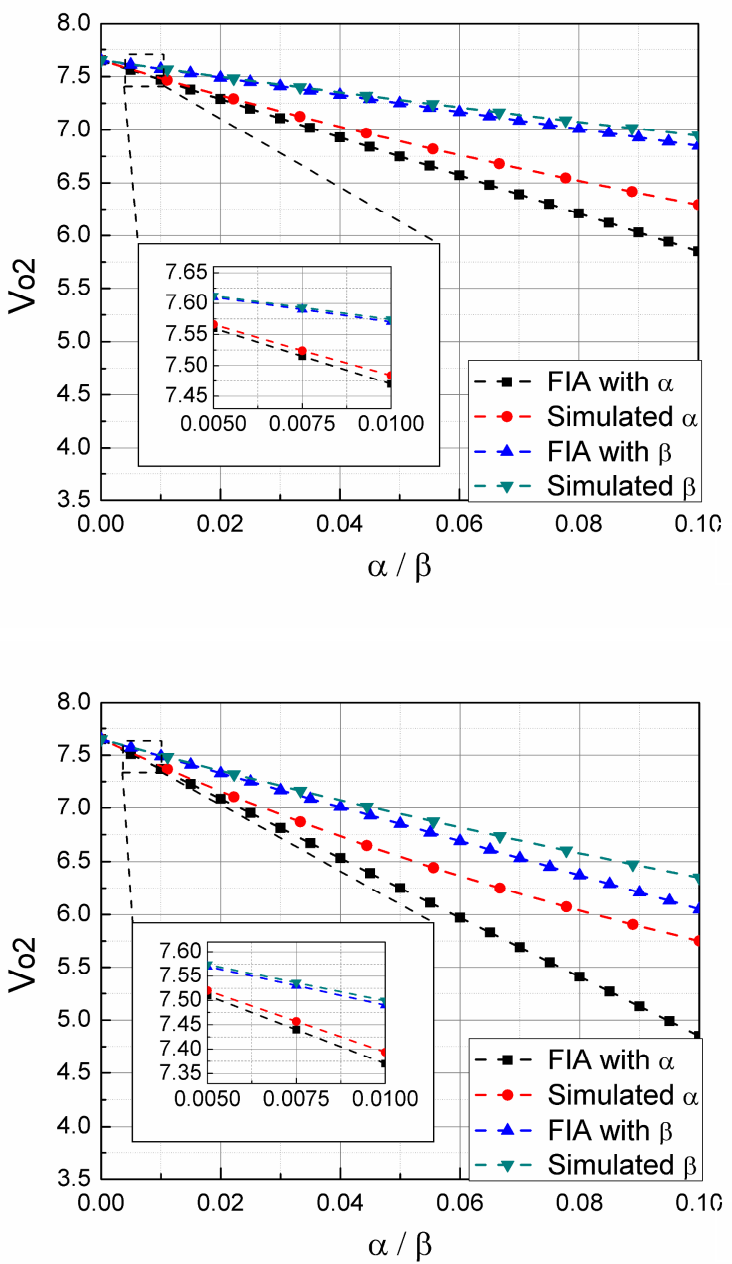

(c)

Fig. 14. (continued)

\section{Design Strategy of Optimal Linear Charge Pumps}

As the linear charge pump is the most efficient on-chip implementation, it is worthwhile to devise a design strategy in optimizing the efficiency for a specified output voltage. Table 4 summarizes the design strategies proposed in [5] and [6], along with our own proposal. The design strategy of [5] has been very successful in optimizing the efficiencies of LQPs and worth repeating in some details. In [5], instead of working directly on $\eta$, the input current $I_{\text {in }}$ consisting of the currents flowing into the negative-plate parasitic capacitors $\beta C_{k}$ were used to find $N_{\text {opt }}$ that minimizes $\mathrm{I}_{\mathrm{in}}$, while $\alpha \mathrm{C}_{\mathrm{k}}$ were left out. In assuming $\alpha=0, \mathrm{~N}_{\text {opt }}$ is computed using (45). The input current $\mathrm{I}_{\text {in }}$ with $\alpha=0$ is derived as [5] 


$$
\left.\mathrm{I}_{\mathrm{in}}\right|_{\alpha=0}=\left(\mathrm{N}+1+\frac{\beta \mathrm{N}^{2}}{\mathrm{~N}+1-\mathrm{M}}\right) \mathrm{I}_{\mathrm{o}} .
$$

Then the flying capacitor $C$ is computed using (21) and (41), and $\eta$ can be obtained from (35), all with $\alpha=0$ (Table 4).

The drawback of [5] is in neglecting $\alpha C_{k}$. In present-day technology, an MIM (metal-insulator-metal) capacitor has a capacitance of $1 \mathrm{fF} / \mu^{2}$. The bottom-plate (usually implemented as negative-plate) parasitic parameter is $\beta=0.01 \sim 0.05$, while the top-plate (usually implemented as positive-plate) parasitic parameter is $0.1 \mathrm{fF} / \mu \mathrm{m}$ of perimeter. If the unit capacitor is $1.6 \mathrm{pF}$, it could be realized by a $40 \mu \mathrm{m} \times 40 \mu \mathrm{m}$ MIM capacitor, and $\alpha=0.01$. If the unit capacitor is $400 \mathrm{fF}$, then $\alpha$ increases to 0.02 . Moreover, when switches or diodes are taken into consideration, additional parasitic capacitors will be added to both plates. Therefore, the assumption that $\alpha C_{k}$ are negligible may not be justified.

Table 4. Comparison of analyses and optimization methods of LQPs

\begin{tabular}{|c|c|c|c|}
\hline & [5] & [6] & This work \\
\hline & $\alpha=0, \beta \neq 0$ & $\alpha \neq 0, \beta \neq 0$ & $\lambda=\alpha+\beta+\alpha \beta$ \\
\hline $\mathrm{N}_{\mathrm{opt}}$ & $\left(1+\sqrt{\frac{\beta}{1+\beta}}\right)(\mathrm{M}-1)$ & $\mathrm{N}$ is given a priori & $(1+\alpha)\left(1+\sqrt{\frac{\lambda}{1+\lambda}}\right)(\mathrm{M}-1)$ \\
\hline$\delta=\frac{\mathrm{I}_{\mathrm{o}} \mathrm{T}}{\mathrm{CV}_{\mathrm{dd}}}$ & $\frac{\mathrm{N}+1-\mathrm{M}}{\mathrm{N}}$ & $\mathrm{C}$ is given a priori & $\frac{N+1+\alpha-(1+\alpha) M}{N}$ \\
\hline $\mathrm{V}_{\mathrm{o}}$ & $(\mathrm{N}+1) \mathrm{V}_{\mathrm{dd}}-\frac{\mathrm{NI}_{\mathrm{o}} \mathrm{T}}{\mathrm{C}}$ & $\begin{array}{c}\frac{\mathrm{N}+1+\alpha}{1+\alpha} \mathrm{V}_{\mathrm{dd}}- \\
\frac{\mathrm{NI}_{\mathrm{o}} \mathrm{T}}{(1+\alpha) \mathrm{C}}\end{array}$ & $\frac{\mathrm{N}+1+\alpha}{1+\alpha} \mathrm{V}_{\mathrm{dd}}-\frac{\mathrm{NI}_{\mathrm{o}} \mathrm{T}}{(1+\alpha) \mathrm{C}}$ \\
\hline$\eta$ & $\frac{M}{N+1+\frac{N \beta}{\delta}}$ & $\frac{\mathrm{M}}{\mathrm{N}+1+\frac{(2 \mathrm{~N}+1) \alpha}{1+\alpha}+\frac{\mathrm{N} \beta}{\delta}}$ & $\frac{(1+\alpha) \mathrm{M}}{\mathrm{N}+1+\alpha+\frac{\mathrm{N}(\alpha+\beta+\alpha \beta)}{\delta}}$ \\
\hline
\end{tabular}

An attempted to perfect the analysis of [5] by including the input currents of $\alpha C_{k}$ was proposed in [6]. Ref. [6] did not show how $\mathrm{N}$ is computed, and it is reasonable to use $\mathrm{N}_{\mathrm{opt}}$ and $\delta$ as computed in [5]. By using the formula for $\mathrm{V}_{\mathrm{o}}$ due to [2] that includes $\alpha C_{k}, V_{o}$ was accurately estimated (Table 4). However, all $\alpha C_{k}$ were assumed to be charged in both phases (that gives the factor $2 \mathrm{~N}+1$ shown in Table 4) and was thus not accurate enough. Moreover, the parameter $\mathrm{V}_{\mathrm{C} / \mathrm{D}}$ in [6] was not derived correctly. 
Our proposed design strategy complements that of [5] by correctly accounting for the effects of $\alpha C_{k}$. By grouping the denominator of (34) as $V_{d d} I_{i n} T$, the input current $\mathrm{I}_{\text {in }}$ is obtained as

$$
I_{\text {in }}=\left(N+1+\alpha+\frac{(\alpha+\beta+\alpha \beta) N^{2}}{N+1+\alpha-(1+\alpha) M}\right) \frac{I_{o}}{1+\alpha} .
$$

The dependence of $\alpha$ in (92) cannot be obtained very easily through ad hoc addition of $\alpha \mathrm{C}_{\mathrm{k}}$ terms to (91), but it can be handled correctly through using the systematic application of the charge balance law as shown in Section 4. It is obvious that minimizing $I_{\text {in }}$ of (92) is the same as minimizing $\gamma$ of (43).

Following the steps in [5], $\mathrm{N}_{\text {opt }}$ is first computed using (44) that correctly accounts for $\alpha C_{k}$ (Table 4). From Fig. 14, it is clear that $\eta_{\max }$ decreases as $\mathrm{N}$ increases for the same $\alpha$ and $\beta$. Qualitatively, using a larger $\mathrm{N}$ to realize the same output conversion ratio $M$ means that more $C_{k}$ have to be used, and there will be more losses from $\alpha C_{k}$ and $\beta C_{k}$. Therefore, a smaller $\mathrm{N}$ is preferred if the realized $\mathrm{V}_{\mathrm{o}}$ is acceptable for that application. After $\mathrm{N}$ is determined, one then has two choices in computing $\mathrm{C}$ : the first one is to compute $\mathrm{C}$ using (39), such that maximum efficiency is guaranteed, but the realized output voltage may deviate from the required $\mathrm{V}_{\mathrm{o}}$; and the second one is to compute $\mathrm{C}$ using (41) such that $\mathrm{V}_{\mathrm{o}}=\mathrm{MV}_{\mathrm{dd}}$ as required. Here, we propose that we should compute $\mathrm{C}$ using (41) whatsoever to make sure that the realized output voltage is the same as the specification, while the degradation in efficiency is too small to be of concern. Our argument is as follow. When $\delta$ is not equal to $\delta_{\text {opt }}$, the efficiency $\eta$ can be obtained from $\eta_{\max }$ using Taylor's series expansion:

$$
\eta=\eta_{\max }+\left.\frac{\mathrm{d} \eta}{\mathrm{d} \delta}\right|_{\delta_{\mathrm{opt}}} \Delta \delta+\left.\frac{1}{2} \frac{\mathrm{d}^{2} \eta}{\mathrm{d} \delta^{2}}\right|_{\delta_{\mathrm{opt}}} \Delta \delta^{2}+\cdots
$$

The maximum efficiency is obtained by finding the condition for $d \eta / d \delta=0$; hence, the first order term is zero. For the second derivative, it can easily be shown that

$$
\left.\frac{\mathrm{d}^{2} \eta}{\mathrm{d} \delta^{2}}\right|_{\delta_{\mathrm{opt}}}=\frac{-2 \mu}{\mu \lambda+\delta_{\mathrm{opt}}}
$$

giving

$$
\eta \approx \eta_{\max }-\mu\left(1-\frac{1}{\sqrt{1+\frac{1}{\mu^{2} \lambda}}}\right)\left(\frac{\Delta \delta}{\delta_{\text {opt }}}\right)^{2} .
$$

In general, the coefficient of the $\left(\Delta \delta / \delta_{\text {opt }}\right)^{2}$ term is smaller than unity. For $\Delta \delta / \delta_{\text {opt }}=$ \pm 0.1 ( $10 \%$ deviate from the optimal value), the decrease in efficiency is only less than $1 \%$. Hence, we conclude that $\mathrm{C}$ should be computed using (41). 
As an example, let us design a charge pump that has an average output voltage $\mathrm{V}_{\mathrm{o}}$ of $5 \mathrm{~V}(\mathrm{M}=5)$ with the following specifications: the input voltage $\mathrm{V}_{\mathrm{dd}}$ is $1 \mathrm{~V}$, the load current $\mathrm{I}_{\mathrm{o}}$ is $10 \mu \mathrm{A}$, and the switching frequency $\mathrm{f}_{\mathrm{s}}$ is $10 \mathrm{MHz}$. The positive-plate and negative-plate parameters are $\alpha=0.01$ and $\beta=0.06$, respectively. The load capacitor is $\mathrm{C}_{\mathrm{L}}=1 \mathrm{nF}$.

For the design according to [5], $\mathrm{N}_{\text {opt }}$ and $\delta$ are computed using the corresponding formulae in Table 4. $\mathrm{N}_{\text {opt }}$ is computed to be 4.95, and naturally $\mathrm{N}$ is taken as 5 . As $\alpha$ is assumed to be zero while actually it is 0.01 , both the output voltage $V_{o}$ and the efficiency $\eta$ are overestimated, as the simulation results in Table 5 show.

For the design according to [6], $\mathrm{N}_{\text {opt }}$ and $\delta$ are obtained as in [5]. As the accurate formula for $\mathrm{V}_{\mathrm{o}}$ is used, the theoretical value $(4.9604 \mathrm{~V})$ is very close to the simulated value $(4.960 \mathrm{~V})$. Moreover, as the effects of $\alpha \mathrm{C}_{\mathrm{k}}$ are partially accounted for, the theoretical efficiency $(0.6519)$ is closer to the simulated value $(0.6466)$ than that of [5] (0.6667).

For our proposed design, $\mathrm{N}_{\text {opt }}$ is computed using (44), and the value is 5.08. We choose $\mathrm{N}=5$ instead of $\mathrm{N}=6$ because it is closer to 5.08 , and we can use (41) to compute $\delta$ that still satisfies $M=5$. The reduction factor $\delta$ is computed to be 0.192 . Both the theoretical and the simulation values are $\mathrm{V}_{\mathrm{o}}=5.00 \mathrm{~V}$. For computing the efficiency, the theoretical value $(0.6434)$ is also very close to the simulated value (0.6436). To maximize the efficiency, we may re-compute $\delta$ to obtain $\delta_{\text {opt }}=0.2134$, and the corresponding $\eta_{\max }$ is 0.6449 . From (95), the coefficient of $\left(\Delta \delta / \delta_{\text {opt }}\right)^{2}$ is 0.652 , with $\Delta \delta=0.2134-0.192=0.0214$, and $\Delta \delta / \delta_{\text {opt }}=0.1$. The efficiency is then $\eta=0.6449$ $-0.652 \times 0.1^{2}=0.6384$. Two conclusions can be drawn: (i) the estimated $\eta$ using (95) is less than $1 \%$ from the computed value; and (ii) even with a $10 \%$ deviation from $\delta_{\text {opt }}$, the resultant efficiency is still very close to $\eta_{\max }$. A plot of $\eta$ versus $\delta$ in the vicinity of $\delta_{\text {opt }}$, along with Cadence simulations, is shown in Fig. 15.

Table 5. Comparison of analyses with simulations

\begin{tabular}{|c|c|c|c|}
\hline & Analysis & Simulation & \% error \\
\hline \multicolumn{4}{|c|}{ [5] with $\mathrm{N}=5, \mathrm{C}=5 \mathrm{pF}$} \\
\hline $\mathrm{V}_{\mathrm{o}}$ & $5.000 \mathrm{~V}$ & $4.960 \mathrm{~V}$ & $0.8 \%$ \\
\hline$\eta$ & $66.67 \%$ & $64.47 \%$ & $3.41 \%$ \\
\hline \multicolumn{4}{|c|}{ [6] with $\mathrm{N}=5, \mathrm{C}=5 \mathrm{pF}$} \\
\hline $\mathrm{V}_{\mathrm{o}}$ & $4.9604 \mathrm{~V}$ & $4.960 \mathrm{~V}$ & $0.008 \%$ \\
\hline$\eta$ & $65.19 \%$ & $64.47 \%$ & $1.12 \%$ \\
\hline \multicolumn{4}{|c|}{ This work with $\mathrm{N}=5, \mathrm{C}=5.21 \mathrm{pF}$} \\
\hline $\mathrm{V}_{\mathrm{o}}$ & $5.00 \mathrm{~V}$ & $5.00 \mathrm{~V}$ & $0 \%$ \\
\hline$\eta$ & $64.34 \%$ & $64.36 \%$ & $0.031 \%$ \\
\hline \multicolumn{4}{|c|}{ This work with $\mathrm{N}=5, \mathrm{C}=4.72 \mathrm{pF}$} \\
\hline $\mathrm{V}_{\mathrm{o}}$ & $4.894 \mathrm{~V}$ & $4.902 \mathrm{~V}$ & $0.020 \%$ \\
\hline$\eta$ & $64.49 \%$ & $64.51 \%$ & $0.031 \%$ \\
\hline
\end{tabular}




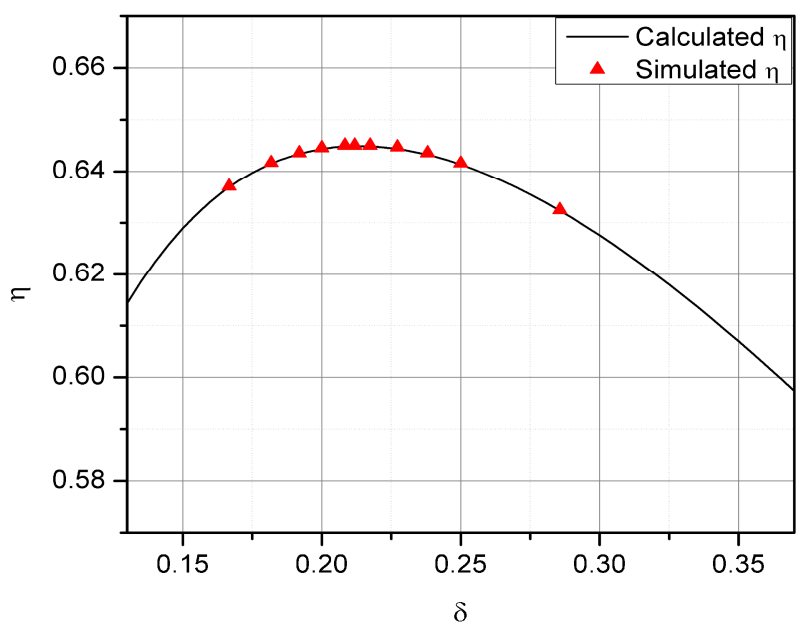

Fig. 15. Simulated $\eta$ vs $\delta$ in the vicinity of $\delta_{\text {opt }}$ with $\alpha=0.01$

\section{Conclusions}

In this research, charge balance law is systematically employed to analyze charge pumps with ideal switches and finite positive-plate and negative-plate parasitic capacitors. Equations for output voltages, output voltage ripples and efficiencies are derived for single-branch and dual-branch linear charge pumps. In computing $\mathrm{V}_{\mathrm{o}}(\mathrm{t})$, a finite load capacitor $C_{L}$ is used, and the result is extended to $C_{L}=\infty$. We observe that $\mathrm{C}_{\mathrm{L}}$ determines the output voltage ripple, but has a negligible effect on the average output voltage. From exact derivations, it is found that $\mathrm{V}_{\mathrm{o} 2}$ is independent of $\mathrm{C}_{\mathrm{L}}$ for both single-branch and dual-branch charge pumps, and can be used to simplify analysis for $\mathrm{C}_{\mathrm{L}}=\infty$. Interpolation could then be performed to obtain $\mathrm{V}_{\mathrm{o} 1}$ and $\mathrm{V}_{\mathrm{o} 3}$ for single-branch charge pumps, and $\mathrm{V}_{\mathrm{o} 1}$ for dual-branch charge pumps.

Besides linear charge pumps, Fibonacci and exponential charge pumps are analyzed. The exact analysis of FQPs and EQPs are too complex and no insight could be obtained. Instead, we proposed a first iteration approximation analysis to obtain reasonably accurate results. Our findings are as follows. (1) If $C_{L}=\infty$, the performance of single-branch and dual-branch charge pumps are the same, and the single-branch LQP is preferred due to its lower complexity. (2) If parasitic capacitors are negligible, LQP, FQP and EQP give the same total capacitance for the same output voltage. (3) In the presence of parasitic capacitors, LQP is the best topology that could achieve the highest output voltage.

Efficiency optimization of LQPs is through first computing the optimal number of stages, followed by finding the reduction factor $\delta$ that achieves the required average output voltage $\mathrm{V}_{\mathrm{o}}$. Using $\delta_{\text {opt }}$ to maximize the efficiency $\eta$ may not be necessary as the sensitivity of $\eta$ w.r.t. $\delta$ is very low. From the obtained $\delta$ we may then choose to change either the flying capacitor $\mathrm{C}$ or the switching frequency $\mathrm{f}_{\mathrm{s}}$ or both for the design. All the analyses are confirmed by Cadence Spectre simulations. 


\section{References}

1. Brugler, J.S.: Theoretical performance of voltage multiplier circuits. IEEE J. Solid-State Circ. 6(3), 132-135 (1971)

2. Dickson, J.: On-chip high-voltage generation in MNOS (NMOS) integrated circuits using an improved voltage multiplier technique. IEEE J. Solid-State Circ. 11(3), 374-378 (1976)

3. Witters, J.S., Groeseneken, G., Maes, H.E.: Analysis and modeling of on-chip high-voltage generator circuits for use in EEPROM circuits. IEEE J. Solid-State Circ. 24(5), 1372-1380 (1989)

4. Tanzawa, T., Atsumi, S.: Optimization of word-line booster circuits for low-voltage flash memories. IEEE J. Solid-State Circ. 34(8), 1091-1098 (1999)

5. Palumbo, G., Pappalardo, D., Gaibotti, M.: Charge-pump circuits: power-consumption optimization. IEEE Tran. Circ. Syst. I 49(11), 1535-1542 (2002)

6. Hoque, M., Ahmed, T., McNutt, T., Mantooth, H., Mojarradi, M.: A technique to increase the efficiency of high-voltage charge pumps. IEEE Tran. Circ. Syst. II 53(5), 364-368 (2006)

7. Palumbo, G., Pappalardo, D.: Charge pump circuits: An overview on design strategies and topologies. IEEE Circ. Syst. Mag. 10(1), 31-45 (2010)

8. Tanzawa, T.: A switch-resistance-aware Dickson charge pump model for optimizing clock frequency. IEEE Tran. Circ. Syst. II 58(6), 336-340 (2011)

9. Ueno, F., Inoue, T., Oota, I., Harada, I.: Emergency power supply for small computer systems. In: IEEE Int'1 Symp. Circ. Syst., pp. 1065-1068. IEEE Press, New York (1991)

10. Cernea, R.A.: Charge pump circuit with exponetral (exponential) multiplication. US Patent 5,436,587 (July 25, 1995)

11. Ki, W.H., Su, F., Lam, Y.H., Tsui, C.Y.: N-stage exponential charge pumps, charging stages therefore and methods of operation therefore. US Patent 7,397,299 (July 8, 2008)

12. Ki, W.H.: Gain- and Offset-Compensated Switched-Capacitor Circuits. Ph. D. Thesis, UCLA (June 1995)

13. Ki, W.H., Su, F., Tsui, C.Y.: Charge redistribution loss consideration in optimal charge pump design. In: IEEE Int'l Symp. Circ. Syst., pp. 1895-1898. IEEE Press, New York (2005)

14. Ki, W.H., Lu, Y., Su, F., Tsui, C.Y.: Design and analysis of on-chip charge pumps for micro-power energy harvesting applications. In: IEEE VLSI-SoC, pp. 374-379. IEEE Press, New York (2011)

15. Wu, W.C., Bass, R.M.: Analysis of charge pumps using charge balance. In: IEEE Power Elec. Specialists Conf., pp. 1491-1496. IEEE Press, New York (2000)

16. Han, J., von Jouanne, A., Temes, G.C.: A new approach to reducing output ripple in switched-capacitor-based step-down DC-DC converters. IEEE Tran. Power Elec. 21(6), 1548-1555 (2006)

17. Starzyk, J.A., Jan, Y.W., Qiu, F.: A DC-DC charge pump design based on voltage doublers. IEEE Trans. Circ. Syst. I 48(3), 350-359 (2001)

18. Su, F., Ki, W.H.: Component-efficient multi-phase switched capacitor DC-DC converter with configurable conversion ratios for LCD driver applications. IEEE Trans. Circ. Syst. II 55(8), 753-757 (2008) 